\title{
Making sense of hormone-mediated defense networking: from rice to Arabidopsis
}

\section{David De Vleesschauwer*, Jing Xu and Monica Höfte}

Laboratory of Phytopathology, Department of Crop Protection, Faculty of Bioscience Engineering, Ghent University, Ghent, Belgium

\section{Edited by:}

Benjamin Schwessinger, University of California, Davis, USA

\section{Reviewed by:}

Steven H. Spoel, University of Edinburgh, UK

Ulrich Schaffrath, RWTH Aachen

University, Germany

\section{${ }^{*}$ Correspondence:}

David De Vleesschauwer, Laboratory of Phytopathology, Department of Crop Protection, Faculty of Bioscience Engineering, Ghent University, Coupure Links 653, Ghent 9000, Belgium

e-mail: david.devleesschauwer@ ugent.be
Phytohormones are not only essential for plant growth and development but also play central roles in triggering the plant immune signaling network. Historically, research aimed at elucidating the defense-associated role of hormones has tended to focus on the use of experimentally tractable dicot plants such as Arabidopsis thaliana. Emerging from these studies is a picture whereby complex crosstalk and induced hormonal changes mold plant health and disease, with outcomes largely dependent on the lifestyle and infection strategy of invading pathogens. However, recent studies in monocot plants are starting to provide additional important insights into the immune-regulatory roles of hormones, often revealing unique complexities. In this review, we address the latest discoveries dealing with hormone-mediated immunity in rice, one of the most important food crops and an excellent model for molecular genetic studies in monocots. Moreover, we highlight interactions between hormone signaling, rice defense and pathogen virulence, and discuss the differences and similarities with findings in Arabidopsis. Finally, we present a model for hormone defense networking in rice and describe how detailed knowledge of hormone crosstalk mechanisms can be used for engineering durable rice disease resistance.

Keywords: hormone signaling, plant immunity, Oryza sativa, plant defense, disease resistance, microbial virulence, pathogen

\section{INTRODUCTION}

Plant hormones are small signaling molecules that are essential in the regulation of plant growth, development, reproduction, and survival. They not only orchestrate intrinsic developmental programs but also convey environmental inputs and drive adaptive responses to a wide variety of biotic and abiotic stresses. Plants typically respond to pathogen infection or herbivore attack with a complex scenario of sequential, antagonistic, or synergistic action of different hormone signals leading to defense gene expression (Robert-Seilaniantz et al., 2011). This interplay or so-called crosstalk among individual hormone pathways enables plants to adjust their inducible defense arsenal to the type of attacker encountered and to use their limited resources in a cost-efficient manner (Pieterse et al., 2009, 2012).

Historically, plant hormone research has been polarized toward the use of the experimentally tractable dicot plant Arabidopsis thaliana. In this model species, the production and joint role of salicylic acid (SA), jasmonic acid (JA), and ethylene (ET) upon pathogen attack is well studied and these three hormones are considered to be the key players in the regulation of the disease signaling pathways. Following microbe perception, plants produce a complex blend of SA, JA, and ET, with the exact combination seemly depending on the infection strategy and lifestyle of the invading pathogen. Although there are exceptions, SA is usually effective against biotrophic pathogens that feed on living plant tissues, whereas cell death-provoking necrotrophic pathogens are commonly deterred by JA- and ET-dependent defenses (Bari and Jones, 2009). Moreover, these two pathways often interact in an antagonistic manner, which has led many authors to suggest that plant immunity follows a binary model with SA and JA/ET having opposite roles. In compliance with this concept, many other hormones, including abscisic acid (ABA), gibberellins (GAs), auxins and cytokinins (CKs), have been shown to differentially affect Arabidopsis resistance against biotrophs and necrotrophs by feeding into the SA-JA-ET cascades (Robert-Seilaniantz et al., 2007, 2011).

Although Arabidopsis has been an excellent model for studying hormone defense networking, recent studies using alternative model systems such as rice (Oryza sativa L.) are starting to provide important new insights, often revealing unique complexities (De Vleesschauwer et al., 2013; Yang et al., 2013). Consumed daily by more than 3 billion people worldwide and accounting for up to $50 \%$ of the daily caloric uptake of the world's poor, rice is arguably the world's most important staple food. Moreover, due to its relatively small and fully sequenced genome, its ease of transformation, accumulated wealth of genetic and molecular resources, and extensive synteny and collinearity with other cereals, rice has emerged as an excellent model for molecular genetic studies in monocots (Jung et al., 2008).

Here, we survey recent advances dealing with hormoneregulated defense networking in rice, focusing on interactions between hormone signaling, rice defense, and pathogen virulence. We will discuss the roles of the various hormone pathways in rice, paying special attention to the differences and similarities with findings in Arabidopsis. Finally, we describe how detailed knowledge of hormone defense networking can be used for engineering durable disease resistance in rice and outline some avenues for further research. For more detailed information on innate immune 
mechanisms and hormone biology in rice and other cereals, we refer the reader to a number of excellent recent reviews (Chen and Ronald, 2011; Liu et al., 2013a; Kyndt et al., 2014).

\section{PLANT IMMUNITY AND HORMONAL REGULATION}

Plants live in complex environments where they are continuously subjected to attack by microbial pathogens and herbivorous insects. To combat infection by these deleterious organisms, plants possess a multilayered immune system that is composed of two interconnected branches, termed PAMP-triggered immunity (PTI) and effector-triggered immunity (ETI). PTI is triggered by perception of invariant pathogen- or microbe-associated molecular patterns (PAMPs/MAMPs). Several PAMPs have been identified thus far, including bacterial flagellin, lipopolysaccharides (LPSs) and elongation factor $\mathrm{Tu}$ (EF-Tu), fungal chitin and oomycetes cellulose-binding elicitor proteins (Schwessinger and Ronald, 2012). PAMPs are detected by means of highaffinity membrane-bound receptor proteins referred to as pattern recognition receptors (PRRs). Showing structural and functional similarities with animal Toll-like receptors, PRRs typically consist of an extracellular leucine-rich repeat (LRR) domain and an intracellular kinase domain (Zipfel, 2008). Perception of MAMPs by PRRs initiates a diverse set of downstream signaling events, leading to a basal level of resistance (Schwessinger and Ronald, 2012; Macho and Zipfel, 2014). In most cases, PTI is sufficient to impede pathogen colonization and suppress disease development. Successful pathogens, however, dodge PTI-based surveillance by delivering small effector proteins in the apoplast or the cytosol of host cells, resulting in effectortriggered plant susceptibility (ETS). Plants, in turn, have adapted to recognize these attacker-specific effectors by means of transmembrane or intracellular resistance proteins, triggering a superimposed layer of defense termed ETI (Jones and Dangl, 2006).

Both PTI and ETI are associated with the activation of a stereotypical set of physical and biochemical defense responses that are instrumental in halting pathogen ingress. These defenses include the biosynthesis of antimicrobial secondary metabolites, stomatal closure, bursts of reactive oxygen species, and local strengthening of plant cell walls by callose and lignin (Pieterse et al., 2009). Seminal experiments with mutant and transgenic plants in tobacco and Arabidopsis which are impaired in the biosynthesis, perception or signaling of specific hormones have demonstrated the central importance of plant hormones in the regulation of these downstream immune events. Upon pathogen attack, plants synthesize a complex blend of hormones, leading to the activation of distinct sets of defense-related genes (Glazebrook et al., 2003; Pieterse et al., 2012). It is thought that this signal signature, which differs considerably in timing, quantity, and composition according to the type of attacker encountered, plays a pivotal role in the regulation of the plant's immune network and eventually determines the specific nature of the defense response triggered (De Vos et al., 2005; Mur et al., 2006).

\section{SALICYLIC ACID}

Salicylic acid is a natural phenolic compound that plays wellknown roles in the regulation of a wide variety of immune responses triggered by PAMPs and microbe-secreted effector proteins (Vlot et al., 2009; Boatwright and Pajerowska-Mukhtar, 2013). During PTI and ETI, endogenous levels of SA and its conjugates increase dramatically, preceding the induction of pathogenesis-related (PR) proteins and the onset of local and systemic acquired resistance (SAR; Metraux et al., 1990; Malamy and Klessig, 1992; Mishina and Zeier, 2007; Tsuda et al., 2009). SA biosynthesis in higher plants is derived from the shikimatephenylpropanoid pathway, and may occur via two different branches. In Arabidopsis, basal SA production predominantly occurs via the conversion of phenylalanine to cinnamic acid by the enzyme phenylalanine ammonia lyase, whereas the majority of pathogen-induced SA production derives from isochorismate (Vlot et al., 2009).

In rice, however, the role of SA biosynthesis in disease resistance is still poorly understood, and even controversial. Driving the debate initially was the observation that rice accumulates high basal levels of SA (8-37 $\mu \mathrm{g} \mathrm{g}^{-1}$ fresh weight) that do not change significantly upon pathogen attack (Silverman et al., 1995). In contrast, in tobacco and Arabidopsis, basal levels of SA are low (less than $100 \mathrm{ng} \mathrm{g}^{-1}$ fresh weight), but increase by two orders of magnitude following infection (Malamy and Klessig, 1992). Moreover, unlike dicots where de novo synthesized SA is rapidly converted into SA $\beta$-glucoside, in rice most SA is present in the free acid form (Silverman et al., 1995). Interestingly, these high levels of free SA are hypothesized to function as a preformed antioxidant, protecting rice plants from oxidative damage caused by aging, pathogen attack, or abiotic stress (Yang et al., 2004).

Despite its high endogenous SA content, rice is not insensitive to exogenously administered SA, but this is plant age-dependent. For instance, topical application of SA triggers resistance to the hemibiotrophic blast fungus Magnaporthe oryzae in adult plants but not in young seedlings (Iwai et al., 2007). Moreover, synthetic SA analogs such as probenazole, benzothiadiazole (BTH), and tiadinil induce defense responses in rice and, unlike in Arabidopsis, enhance resistance to a wide range of pathogens with different lifestyles and infection strategies, including Magnaporthe oryzae, the (hemi)biotrophic bacterial leaf blight pathogen Xanthomonas oryzae pv. oryzae (Xoo) and the necrotrophic root pathogens Pythium graminicola and Hirschmanniella oryzae (Shimono et al., 2007; De Vleesschauwer et al., 2008, 2012; Nahar et al., 2012; Xu et al., 2013). Considering that tiadinil and BTH act downstream of SA biosynthesis and that SA-deficient rice plants expressing the bacterial salicylate hydroxylase $N a h G$ display unaltered $P R$ gene expression (Yang et al., 2004), these findings strongly suggest that the signaling action of SA, rather than its de novo biosynthesis, is an important factor mediating defense mobilization in rice.

Considerable differences between rice and Arabidopsis are also evident in the function of the upstream SA regulator phytoalexin deficient 4 (PAD4). Arabidopsis PAD4 encodes a lipase-like protein that functions in ETI and basal immunity against biotrophic pathogens (Jirage et al., 1999; Lipka et al., 2005). AtPAD4 is also postulated to work in a positive feedback loop to promote SA biosynthesis in concert with another lipase-like protein, enhanced disease susceptibility 1 (AtEDS1; Zhou et al., 1998; Feys et al., 2001). Recent findings by the Wang lab, however, point to a very 
different function of PAD4 in rice (Ke et al., 2014). Unlike AtPAD4 which encodes a nucleocytoplasmic protein, OsPAD4 is situated in the plasma membrane. Moreover, OsPAD4-induced resistance to $X o o$ and the hemibiotrophic leaf streak pathogen $X$. oryzae pv. oryzicola (Xoc) does not involve SA-responses, but is associated with the accumulation of JA and the expression of JA-responsive genes.

Downstream of SA biosynthesis, the SA pathway in rice shares several signaling components with the SAR pathway in Arabidopsis, including the master regulatory protein NPR1. During SAR, SA-induced redox changes reduce the intermolecular disulphide bonds that normally keep NPR1 in an inactive oligomeric state in the cytosol (Tada et al., 2008). This reduction in turn releases monomeric NPR1, which is translocated to the nucleus where it interacts with TGA transcription factors (TFs) to activate defense gene expression (Zhang et al., 1999; Cheng et al., 2009). Recently, it was reported that NPR1 as well as its paralogs NPR3 and NPR4 may also serve as SA receptor proteins (Fu et al., 2012; Wu et al., 2012).

To date, five NPR1-like genes have been identified in the rice genome, among which OsNPR1 (also called OsNH1) is the closest homolog of AtNPR1 (Yuan et al., 2007). Ectopic expression of OsNPR1 in rice induced constitutive accumulation of $P R$ transcripts, conferring high levels of resistance to Magnaporthe oryzae and Xoo (Chern etal., 2005; Yuan et al., 2007; Sugano et al., 2010). By contrast, in rice and Arabidopsis overexpressing AtNPR1, defense-related genes are not activated until induced by abiotic stress, pathogen attack or BTH treatment (Cao et al., 1998; Fitzgerald et al., 2004).

Moreover, unlike the situation in Arabidopsis where nearly 99\% of all BTH-responsive genes are controlled by NPR1 (Wang et al., 2006), many SA-responses in rice are controlled by a second master regulatory protein called OsWRKY45 which functions parallel to OsNPR1 (Shimono et al., 2007; Sugano et al., 2010). OsWRKY45 was originally identified as a BTH-responsive TF that is essential for resistance gene- and plant activator-mediated resistance to Xoo and Magnaporthe oryzae (Shimono et al., 2007, 2012; Inoue et al., 2013). Interestingly, OsWRKY45 also has been linked to stress responses in the endoplasmic reticulum (ER). Hayashi et al. (2012) showed that detection of ER stress by the transmembrane sensor protein IRE1 not only induces rapid expression of ER quality control-related chaperones, but also suppresses expression of $P R$ genes and enhances transcription of OsWRKY45 in an OsbZIP50-dependent manner. In contrast, concomitant activation of the SA response and ER stress induction suppresses the induction of ER quality control genes but promotes activation of OsWRKY45, which in turn triggers SA-responsive gene expression. Therefore, it is not unlikely that the SA response uses ER stress-induced OsWRKY45 to activate defense responses (Hayashi et al., 2012).

Although much remains to be discovered about the precise role of OsWRKY45 in the rice SA signaling pathway, several recent findings have provided new insights into the regulation of OsWRKY45. First, OsWRKY45 seems to be activated at least in part by an SA-dependent phosphorylation cascade controlled by the MAPKs OsMPK4 and OsMPK6 (Ueno et al., 2013). Although it is still unclear how this regulation affects OsWRKY45 activity, one interesting hypothesis is that phosphorylation of OsWKRY45 may facilitate its recruitment to the ubiquitin proteasome system (UPS). Like Arabidopsis NPR1 (Spoel et al., 2009), OsWRKY45 undergoes continuous degradation by the UPS in the nucleus (Matsushita et al., 2013). This UPS-mediated OsWRKY45 turnover likely plays a dual role by preventing spurious defense activation, on the one hand, and promoting the transcriptional activity of OsWRKY45 following SA treatment or pathogen attack, on the other (Matsushita et al., 2013). Interestingly, the same authors failed to show proteasome degradation of OsNPR1 under resting conditions (Matsushita et al., 2013). Whether OsNPR1 undergoes UPS-mediated turnover under pathogen challenge remains to be investigated.

Together, abovementioned findings highlight the unique complexities associated with SA signal transduction in rice. Most notably, the rice SA pathway seems to branch into two sub-pathways controlled by OsNPR1 and OsWRKY45. Recent microarray experiments revealed that almost half of all BTHresponsive genes and over two thirds of all BTH-downregulated genes are dependent on OsNPR1. These downregulated genes include many genes involved in photosynthesis and protein synthesis, suggesting a novel function of OsNPR1 in relocating energy and resources from house-keeping cellular activities to defense reactions (Sugano etal., 2010; Nakayama et al., 2013). In contrast, most genes upregulated by BTH are dependent on OsWRKY45, including many $P R$ genes and a number of well-characterized defense-related TFs such as OsWRKY62, OsNAC4, and OsHSF1 (Takatsuji etal., 2010; Shimono et al., 2012; Nakayama etal., 2013). Together these findings favor a scenario whereby OsNPR1 and OsWRKY45 play different yet complementary roles in the rice SA pathway with OsNPR1 tentatively acting as an energy switch, enabling limited resources to be diverted to OsWRKY45-mediated pathogen defense.

\section{JASMONIC ACID}

Jasmonic acid and its derivatives, collectively known as jasmonates, are lipid-derived hormones that regulate numerous physiological processes, including wound responses, secondary metabolite synthesis, and defense against biotic and abiotic stresses. In dicots, JA is widely believed to be predominantly effective against necrotrophic pathogens and herbivorous insects, whereas SA signaling is typically associated with immunity against biotrophs (Glazebrook, 2005). Although there is evidence for both positive and negative relationships between both pathways, the primary mode of interaction appears to be mutual antagonism, with corresponding trade-offs between biotrophs, on the one hand, and resistance to necrotrophs, on the other (Bostock, 2005). This SAJA antagonism is evolutionary widely conserved and has been reported in as many as 17 plant species in various taxonomic groups (Thaler et al., 2012).

In rice, however, strikingly different results have been obtained with reports implicating JA in resistance against pathogens with distinct lifestyles and infection strategies. Perhaps most intriguingly, studies with JA-modified transgenics and pharmacological inhibitor experiments have uncovered JA as a powerful activator of resistance against the (hemi)biotrophic pathogens 
Xoo and Magnaporthe oryzae (Mei et al., 2006; Yamada et al., 2012; Riemann etal., 2013; Taniguchi et al., 2014). Although it could be argued that JA wards off these hemibiotrophs during the necrotrophic phase of their infection cycle, this is rather unlikely as Xoo has a very short necrotrophic stage while at least in some highly susceptible interactions Magnaporthe oryzae is thought to define a new paradigm for hemibiotropy in which each successive plant cell invasion is biotrophic, but individual invaded cells are no longer viable by the time the fungus moves into the next cell (Nino-Liu et al., 2006; Kankanala et al., 2007).

Consistent with its role in necrotroph resistance of dicots, JA is also effective against necrotrophic rice pathogens such as the sheath blight fungus Rhizoctonia solani. Taheri and Tarighi (2010) showed that topical JA application reduces sheath blight severity by almost $50 \%$ compared to non-treated controls. Enhanced sheath blight resistance concomitant with increased JA levels and induction of JA-responsive gene expression was also observed in rice plants overexpressing the pathogen-inducible TF gene OsWRKY30 (Peng et al., 2012). In addition, the JA pathway is increasingly implicated in rice defenses against insect herbivores and root pathogens such as the biotrophic rice root knot nematode Meloidogyne graminicola (Zhou et al., 2009, 2014; Nahar et al., 2011; Tong et al., 2012; Ye et al., 2012). When considered together, these findings challenge the common assumption that JA triggers resistance to necrotrophs and susceptibility to biotrophs, and suggest that in rice there is no dichotomy between the effectiveness of the JA pathway and the lifestyle of the invading pathogen. Of particular note, it should be mentioned that although the role of $\mathrm{SA}$ in biotroph resistance and JA in necrotroph resistance is clear in many dicot pathosystems, there are also plenty of exceptions to this rule (Thaler et al., 2004; Glazebrook, 2005; Pieterse et al., 2009).

Despite the ability of JA to induce resistance against both (hemi)biotrophic and necrotrophic rice pathogens, several reports indicate that SA-JA antagonism is conserved in rice. In roots, SA attenuated JA-induced expression of the rice $P R$ gene $R S O S P R 10$ and its negative regulator OsERF1 (Takeuchi et al., 2011). Furthermore, in wounded rice plants, JA levels rise whereas SA levels decrease, suggesting negative crosstalk in the direction of JA damping SA action (Lee et al., 2004). Further evidence supporting antagonistic SA-JA signal interactions comes from gene expression experiments demonstrating enhanced transcript accumulation of the JA-responsive genes OsAOS2 and JaMYB in SA-deficient NahG rice (Lee et al., 2001; Mei et al., 2006).

Over the past few years, various regulatory components involved in SA-JA crosstalk have been identified, key among which is NPR1 (Spoel et al., 2003; Pieterse et al., 2012; Thaler et al., 2012; Van der Does et al., 2013). Like its Arabidopsis counterpart, overexpression of OsNPR1 is characterized by strong activation of SA-responsive genes and concomitant suppression of JA marker genes (Yuan et al., 2007). Moreover, similar to the situation in dicots, nuclear localization of OsNPR1 is required for SA-mediated defense gene expression, but not for suppression of JA signaling (Spoel etal., 2003; Yuan etal., 2007). OsNPR1 antisense plants display elevated levels of JA and increased expression of JA biosynthetic genes upon insect infestation (Li et al., 2013). Accordingly, ectopic expression of OsNPR1 not only confers enhanced resistance to Magnaporthe oryzae and Xoo, but also renders plants more susceptible to herbivorous insects. In a similar vein, rice plants overexpressing AtNPR1 are hypersensitive to light (Fitzgerald et al., 2004) and display an increased susceptibility to viral infection and reduced tolerance to abiotic stress (Quilis et al., 2008). OsNPR1 thus seems to act as a positive regulator of SA-dependent pathogen resistance, while suppressing JA-mediated defenses to herbivorous insects and viral infection as well as tolerance to abiotic stresses.

A role in SA-JA crosstalk has also been suggested for OsWRKY13. Functioning upstream of OsNPR1 and OsWRKY45, this TF positively regulates SA-mediated rice defenses while suppressing the JA pathway (Qiu et al., 2007, 2008, 2009; Tao et al., 2009). Recently, OsWRKY13 was also shown to repress drought tolerance by transcriptionally suppressing the downstream TF SNAC1 (Xiao et al., 2013).

Although abovementioned studies clearly indicate the potential for negative SA-JA signal crosstalk, examples of positive interactions have also been reported, both in dicot and monocot systems (Mur et al., 2006; Pieterse et al., 2009). In general, however, positive SA-JA signal interactions appear to be more common in rice than in dicots. Most tellingly in this regard, recent microarray studies showed that unlike in dicots more than half of all BTH- or SAupregulated rice genes are also induced by JA (Garg et al., 2012; Tamaoki et al., 2013). Moreover, similar to the Arabidopsis cpr5, cpr6, cpr22, cet, and hrl1 mutants (Clarke et al., 1998, 2000, 2009; Hilpert et al., 2001; Yoshioka et al., 2001; Devadas et al., 2002), several rice mutant and transgenic lines display simultaneously elevated SA and JA signaling. For instance, rice plants mutated in the hydroperoxide lyase OsHPL3 display strongly enhanced JA levels concomitant with increases in SA production and heightened expression of SA-responsive PR genes (Liu et al., 2012b; Tong et al., 2012). Activation of JA synthesis was also found to prime herbivore-induced SA synthesis in rice plants silenced for the phospholipase D genes OsPLD $\alpha 3$ and OsPLD $\alpha 4$ (Qi et al., 2011), while Pan et al. (2014) reported increased expression of both SA- and JA-biosynthesis genes in sheath blight-resistant rice lines overexpressing the JA and ET-inducible TF JERF1. Together, these findings bring a new twist to the classical crosstalk model and suggest that although hyperactivation of one has the ability to override the other, rice SA and JA pathways may feed into a common defense system that is effective against different types of attackers. In support of this concept, it was previously suggested that SA and JA act synergistically when applied at low concentrations, whereas a high concentration of one hormone antagonizes the other (Mur et al., 2006).

\section{ETHYLENE}

Ethylene is a small gaseous hormone that controls diverse aspects of plant life. In plant immunity, ET is generally thought to act in concert with JA to induce necrotroph resistance while antagonizing SA-mediated biotroph resistance (Derksen et al., 2013). Accumulating evidence, however, indicates that ET can interact both positively and negatively with SA, depending on the infection strategy of the invading pathogen (van der Ent and Pieterse, 2012; Derksen et al., 2013). Like SA and JA, ET is rapidly synthesized 
following PAMP perception (Boller and Felix, 2009; Schwessinger and Ronald, 2012). Although the precise function of ET in PTI is still elusive, recent evidence suggest a combined role of ET and endogenous peptides in an amplification loop required for sustained PTI (Liu et al., 2013b; Tintor et al., 2013).

In rice, accumulation of ET and its coproduct cyanide was found to be indispensable ETI against the hemibiotroph Magnaporthe oryzae (Iwai et al., 2007). Interestingly, activation of ET synthesis was also shown to be responsible for the partial blast resistance of rice plants growing in anaerobic conditions such as moisture-saturated soils or flooded paddies (Singh et al., 2004). Transgenic lines overexpressing OsACS2, a gene encoding the key ET biosynthesis enzyme 1-aminocyclopropane-1-carboxylic acid synthase (ACS), showed increased resistance to both Magnaporthe oryzae and R. solani, whereas silencing of ET biosynthesis genes or the central ET signal transducer OsEIN2b rendered plants more susceptible against Magnaporthe oryzae and the bacterial pathogen Burkholderia glumae (Bailey et al., 2009; Seo et al., 2011).

Abovementioned studies clearly indicate that ET plays an important role in rice defense to various pathogens. However, as in dicots, ET can also act negatively on rice immunity, as was shown for the necrotrophic rice brown spot fungus Cochliobolus miyabeanus. Exogenously applied Ethephon (which is converted to ET in plant cells) strongly promotes disease development in this interaction, whereas genetic or pharmacological disruption of ET signaling resulted in enhanced resistance (De Vleesschauwer et al., 2010). Moreover, gene expression experiments revealed a strong activation of ET signaling in susceptible but not in resistant rice plants. Although preliminary, these findings strongly suggest that C. miyabeanus exploits ET as virulence factor and co-opts the rice ET signaling route to rewire the rice signaling circuitry and antagonize host immunity.

A negative impact of ET on rice disease resistance has also been observed for Xoo. Shen et al. (2011) reported that silencing of the MAPKKK OsEDR1 resulted in reduced expression of ACS genes, low levels of ET, and enhanced resistance to Xoo. Interestingly, this resistance was accompanied with increased SA and JA synthesis and constitutive expression of SA- and JA-marker genes, suggesting that when ET is lowered, levels of SA and JA increase (Shen et al., 2011). Together these observations suggest that ET plays a complex and ambiguous role in the rice immune system, the effect of which may depend not only on the lifestyle and overall infection biology of the attacking pathogen, but also on specialized features of each interaction. In compliance with this concept, $\mathrm{Lu}$ et al. (2014) recently also reported a contrasting role of ET biosynthesis in resistance of rice against chewing and phloem-feeding insects.

\section{ABSCISIC ACID}

Compared with the classic defensive hormones SA, JA, and ET, the role of the 'abiotic stress hormone' $\mathrm{ABA}$ in regulating plant immunity is much less understood, and even controversial. Recent studies in dicots showed divergent and complex effects of ABA on defense responses, including the suppression of SA- and JA/ET-dependent defenses, synergistic crosstalk with JA signaling, suppression of ROS generation, induction of stomatal closure, and stimulation of callose deposition (Asselbergh et al., 2008; Cao et al., 2011). In general, the impact of ABA on plant defense seem to be plant-pathogen interaction-specific, rather than to rely on the lifestyle or infection strategy of the pathogen. In Arabidopsis, for instance, ABA both positively and negatively regulates resistance to the necrotrophic fungi Alternaria brassicicola and Botrytis cinerea, respectively (Adie et al., 2007). The timing of infection and type of tissue are other crucial factors underlying ABA modulation of plant immunity. This is nicely exemplified in Pseudomonas syringae pv. tomato-infected Arabidopsis where ABA prevents pathogen entry by inducing stomatal closure, yet is hijacked by the same pathogen to antagonize post-invasive disease resistance by suppressing SA-dependent defenses in the apoplast (Melotto et al., 2006; Mohr and Cahill, 2007; de Torres-Zabala et al., 2009).

In common with these findings, ABA also plays ambiguous roles in the rice defense-signaling network. We previously showed that exogenous $\mathrm{ABA}$ enhances basal resistance of rice against the necrotroph C. miyabeanus (De Vleesschauwer et al., 2010). This ABA-inducible resistance was associated with restriction of fungal progression in the mesophyll and was dependent on negative crosstalk with the rice ET-signaling pathway (De Vleesschauwer et al., 2010). In a similar manner, it has been proposed that ABA conditions susceptibility to both Magnaporthe oryzae and Xoo by antagonizing effectual SA-mediated defenses upstream or at the level of OsNPR1 and OsWRKY45 (Jiang et al., 2010; Xu et al., 2013). Interestingly, infection by Magnaporthe oryzae and Xoo is tightly associated with greatly elevated ABA levels and extensive reprogramming of ABA-responsive genes (Ribot et al., 2008; Liu et al., 2012a; Xu et al., 2013). Consistent with previous findings in the Arabidopsis-Pseudomonas syringae pv. tomato pathosystem (de Torres-Zabala et al., 2007, 2009; Goel et al., 2008; Ho et al., 2013), it therefore appears that both pathogens may hijack the rice ABA pathway to cause disease. In support of this assumption, Magnaporthe oryzae was recently shown to produce and secrete ABA in vitro and in planta (Jiang et al., 2010). Since ABA has no apparent impact on the pathogen's physiology, one may hypothesize that Magnaporthe oryzae uses its own ABA to activate ABA signaling in host cells, thereby suppressing the SA- and ET-signaling pathways that normally serve to limit pathogen growth (Takatsuji and Jiang, 2014).

Although understanding of molecular components governing signal transduction and sensitivity in the rice ABA signaling network is still in its infancy, accumulating evidence points toward a crucial role of the ABA-inducible protein kinase OsMPK5. OsMPK5 RNAi lines show increased levels of ET and enhanced resistance to multiple hemibiotrophic pathogens including Magnaporthe oryzae, Xoo, Burkholderia glumae and the migratory nematode Hirschmanniella oryzae (Xiong and Yang, 2003; Nahar et al., 2012; Xu et al., 2013); however, they are also impaired in ABA-inducible resistance to $C$. miyabeanus and are hypersensitive to abiotic stresses (Bailey et al., 2009; De Vleesschauwer et al., 2010). Conversely, silencing of the central ET-signal transducer OsEIN2 resulted in enhanced resistance to C. miyabeanus as well as hypersensitivity to Magnaporthe oryzae, Xoo, ABA and abiotic stress (Bailey et al., 2009; De Vleesschauwer et al., 2010). Together, these findings suggest that OsMPK5 and OsEIN2 act as molecular 
switches between the rice ABA and ET pathways, thereby differentially regulating abiotic stress tolerance and $C$. miyabeanus resistance, on the one hand, and defense against hemibiotrophic pathogens, on the other.

Interestingly, OsMPK5 also positively interacts with the JA pathway in protecting rice against chewing herbivores, suggesting positive crosstalk in the direction of ABA boosting JA action (Wang et al., 2013). However, Nahar etal. (2013) reported that ABA disables JA-induced resistance against Hirschmanniella oryzae, indicating that the nature of interaction between these pathways is complex and also attacker dependent.

\section{NEW KIDS ON THE BLOCK: DEVELOPMENTAL HORMONES DO DEFENSE}

Contrary to the classic defense hormones SA, JA, and ET and the 'abiotic stress hormone' ABA, other hormones including auxins, gibberellins, brassinosteroids (BRs), and CKs, were historically best studied for their role in growth and development and only recently emerged as additional players in plant-microbe interactions. Although their precise role and function in orchestrating plant defense is still elusive, recent data are now beginning to unveil how these 'developmental' hormones modulate host immunity, and how microbe-induced perturbations of these classic growth regulators contribute to virulence.

\section{AUXINS}

Auxins, such as indole-3-acetic acid (IAA), are a major class of plant hormones that control a range of cellular processes, including apical dominance, tropistic growth, lateral root formation, vascular tissue development, and regulation of plant senescence. Thus far, studies on Arabidopsis imply that auxin attenuates (hemi)biotroph resistance but enhances plant defenses toward necrotrophic pathogens (Fu and Wang, 2011). In compliance with this concept, auxin and more specifically IAA, also act as virulence factors of the hemibiotrophic rice pathogens Magnaporthe oryzae, Xoo and Xoc, causal agent of bacterial leaf streak disease (Ding et al., 2008; Domingo et al., 2009; Fu et al., 2011). Like many other microbes, these pathogens produce and secrete IAA themselves and also increase IAA biosynthesis and signaling upon infection (Fu etal., 2011). In plants, auxin levels are regulated in part through negative feedback by a group of auxininducible GH3 (Gretchen Hagen 3) family genes that catalyze the conjugation of IAA to various amino acids. Unlike in Arabidopsis where three distinct groups of GH3 enzymes have been identified, only groups I and II are present in rice (Westfall et al., 2010). Up to now, three group II GH3 enzymes have been functionally characterized in rice, namely OsGH3.1, OsGH3.2, and OsGH3.8. Consistent with IAA promoting hemibiotroph susceptibility, rice transformants overexpressing these enzymes displayed reduced levels of IAA and enhanced resistance to Magnaporthe oryzae, Xoo and Xoc (Ding et al., 2008; Domingo etal., 2009; Fu et al., 2011).

In Arabidopsis, auxin is widely believed to antagonize SAmediated defenses against biotrophic pathogens (Zhang et al., 2007; Truman et al., 2010). Two recent papers, however, suggest that auxin can also promote growth of Pseudomonas syringae pv. tomato and disease development in Arabidopsis via a mechanism independent of suppression of SA action (González-Lamothe et al., 2012; Mutka et al., 2013). These findings echoe previous studies in rice where IAA-induced hemibiotroph susceptibility was found to be independent of SA and JA (Ding et al., 2008; Fu et al., 2011). Instead, it has been proposed that pathogentriggered IAA promotes susceptibility by inducing the expression of cell wall-loosening expansions, thereby facilitating pathogen entry and allowing increased nutrient leakage. Notably, OsGH3.2overexpressing plants not only exhibit decreased IAA levels, but also produce less ABA, which may contribute to the resistance against Magnaporthe oryzae and Xoo (Du et al., 2012). In addition, these plants are also more tolerant to cold and oxidative stresses, providing a genetic strategy for breeding rice with broad-spectrum stress tolerance using $\mathrm{GH} 3$ family genes. In this context, it will be particularly interesting to assess whether auxin promotes resistance to necrotrophic rice pathogens, as was previously shown in Arabidopsis (Llorente et al., 2008).

\section{CYTOKININS}

Cytokinins are a group of $N^{6}$-substituted adenine derivatives that orchestrate myriad growth and developmental processes in plants. As one of the latest hormones to be linked with immunity, the precise role of CKs in plant immunity remains to be fully elucidated. Historically, CKs are associated with disease symptoms and morphological anomalies, such as fasciation, senescence, and the formation of galls, tumors and so-called 'green islands' (Grant and Jones, 2009). Many fungal and bacterial pathogens can produce CK themselves and/or increase CK synthesis in plants (Siemens et al., 2006; Walters et al., 2008; Naseem et al., 2014). Moreover, pathogens may also activate plant CK signaling in order to suppress host immunity. For instance, it was recently shown that Pseudomonas syringae pv. tomato deploys the effector HopQ1 to activate plant CK signaling and suppress PTI via down-regulation of the flagellin receptor gene FLS2 (Hann et al., 2014).

Although these observations indicate a role of CKs in promoting pathogen virulence, recent work has revealed that CKs can also augment plant immunity against a fairly broad range of pathogens exhibiting different lifestyles (Swartzberg et al., 2008; Grosskinsky et al., 2011; Argueso et al., 2012; Naseem et al., 2012, 2014). Argueso et al. (2012) argued that the levels of CK are important in determining the amplitude of plant immunity. In this study, low concentrations of the CK benzyl adenine (BA) promoted susceptibility of Arabidopsis to the biotroph Hyaloperonospora arabidopsidis, whereas high BA concentrations enhanced disease resistance by priming the SA defense pathway. Biochemical analyses revealed that this positive $\mathrm{CK}-\mathrm{SA}$ crosstalk is mediated through a direct interaction between the CK-activated TF ARR2 and the SA response factor TGA3, resulting in potentiated promoter binding of TGA3 and increased expression of SA-dependent defense genes (Choi et al., 2010, 2011). Meanwhile, SA feedback-inhibits CK signaling, which may serve to fine-tune the effect of CK in plant immunity (Argueso et al., 2012). In tobacco, however, a different mechanism appears to be operative. In this plant species, CK enhances resistance to Pseudomonas syringae pv. tobacco independently of SA, indicating that nuanced, species-specific mechanisms underlie CK's immune-regulatory function (Grosskinsky et al., 2011). 
Although exogenous application of $\mathrm{CK}$ at low and high concentrations did not alter Magnaporthe oryzae progression in rice, CK was found to synergistically interact with SA to activate $P R$ genes in detached leaf assays (Jiang et al., 2013). A follow-up study by the same authors revealed that CK also joins forces with SA to trigger the production of diterpenoid-type phytoalexins in an OsWRKY45-dependent manner (Akagi et al., 2014). Paradoxically, Magnaporthe oryzae secretes CK itself and activates CK signaling in infected leaves, which may facilitate blast infection by increasing the sink strength of infected tissues (Jiang et al., 2013).

\section{BRASSINOSTEROIDS}

Brassinosteroids are a unique group of plant steroidal hormones that play pivotal roles in cell expansion and division, differentiation and reproductive development. Although BRs have long been seen as mainly positive players in plant immunity, recent findings in both dicots and rice suggest a more complex situation, with positive, negative as well as neutral BR effects being reported that are seemingly independent of either the plant species or type of pathogen involved (De Bruyne et al., 2014). In rice, for instance, BR promotes resistance to the hemibiotrophic leaf pathogens Xoo and Magnaporthe oryzae, while inducing susceptibility to the hemibiotrophic root-knot nematode Meloidogyne graminicola and the necrotrophic oomycete Pythium graminicola (Nakashita et al., 2003; De Vleesschauwer et al., 2012; Nahar et al., 2013).

Accordingly, recent studies have revealed a wide variety of underpinning mechanisms, ranging from orchestration of oxidative metabolism and secondary metabolite production to modulation of PAMP perception and ensuing PTI signaling (De Bruyne etal., 2014). Depending on among others the relative hormone concentration and their effect on the BR co-receptor BAK1, BRs can act both antagonistically and synergistically with PTI responses (Albrecht et al., 2012; Belkhadir et al., 2012; Lozano-Durán etal., 2013; Shi et al., 2013). In addition, BRs have been found to cross-communicate with a range of other hormones, including SA, JA, ABA, auxins, and gibberellins (De Bruyne etal., 2014). Consistent with its apparent pluriform role in regulating plant immune responses, the nature and direction of this BR hormone crosstalk can vary widely. For instance, whereas there is evidence for synergistic BR-SA crosstalk in Arabidopsis, previous studies with rice revealed that BR enhances resistance to Xoo and Magnaporthe oryzae in an SA-independent manner while disabling SA-mediated defenses against root pathogens (Nakashita et al., 2003; Divi et al., 2010; De Vleesschauwer et al., 2012). Much like gibberellins and CKs, BRs thus seem to play ambiguous roles in the plant defense network, the effect of which may depend not only on the pathogen's lifestyle and infection strategy, but also on spatial and temporal conditions.

\section{GIBBERELLINS AND DELLA PROTEINS}

Gibberellins are a class of tetracyclic diterpenoid hormones that affect nearly every aspect of plant growth and development. According to current concepts, GAs promotes plant growth by inducing the degradation of a class of nuclear proteins, called DELLAs. Arabidopsis mutants lacking four of the five DELLA proteins showed attenuated induction of the JA marker gene $P d f 1.2$, resulting in enhanced susceptibility to the necrotrophic fungus Alternaria brassicicola (Navarro et al., 2008). In contrast, the same mutants exhibited increased levels of resistance to the hemibiotrophic bacterium Pseudomonas syringae pv. tomato accompanied with elevated levels of SA (Navarro et al., 2008). On the basis of these and other findings, it was proposed that DELLAs modulate the strength of SA/JA signaling during plant immunity, promoting JA perception and/or signaling, and repressing SA biosynthesis and signaling. Accordingly, pretreatment with GA restricts JA signaling, resulting in enhanced SA signaling and increased biotroph resistance (Navarro et al., 2008).

In rice, however, strikingly different results have been obtained in that exogenous GA was found to enhance susceptibility against the hemibiotrophic pathogens Xoo and Magnaporthe oryzae (Yang et al., 2008). Moreover, ectopic expression of a GA-deactivating enzyme designated elongated uppermost internode (EUI) significantly reduced rice SA and JA levels and enhanced resistance to the latter pathogens, whereas EUI loss-of-function mutations led to increased susceptibility (Yang et al., 2008). Other mutants deficient in biosynthesis or perception of GA showed similar gain-of-resistance phenotypes when challenged with either Xoo or Magnaporthe oryzae (Tanaka et al., 2006; De Vleesschauwer et al., 2013; Qin et al., 2013). On the other hand, GA was shown to be a positive player in resistance against the necrotrophic root pathogen Pythium graminicola (De Vleesschauwer et al., 2012). Therefore, opposite to the situation in Arabidopsis, rice GA signaling appears to induce susceptibility to hemibiotrophic pathogens and resistance to necrotrophs.

Although much remains to be discovered about the precise mechanisms via which GA and DELLAs modulate plant immunity, recent studies have implicated DELLAs in a variety of processes, including the regulation of oxidative and energy metabolism, cell wall development, and cytoskeleton architecture (De Bruyne et al., 2014). Moreover, evidence is accumulating that DELLAs orchestrate plant immunity via competitive binding to JA ZIM-domain (JAZ) proteins, a family of JA signaling repressors. JAZ proteins bind and inhibit the activity of numerous TFs, including the key JA transcriptional activator MYC2 (Kazan and Manners, 2012, 2013). Recently, three groups have shown that DELLAs compete with MYC2 for binding to JAZs, thereby releasing free MYC2 to activate JA-responsive gene expression and, hence, increase resistance to necrotrophic pathogens (Hou et al., 2010; Wild et al., 2012; Yang et al., 2012). In the presence of GA, however, DELLAs are rapidly degraded, leading to inhibitory JAZ-MYC2 interactions and disruption of JA signaling. This socalled 'relief of repression' model not only elegantly explains how plants balance growth and defense responses, but also offers novel insights into how GA disables JA-mediated necrotroph resistance by degrading DELLAs and releasing JAZs to bind and inhibit MYC2.

Consistent with these findings in Arabidopsis, Yang et al. (2012) demonstrated that SLR1, the only DELLA in rice, serves as a main target of JA-mediated growth inhibition and is required for fullscale activation of JA-responsive gene expression in rice. In turn, JA treatment protects SLR1 from degradation by exogenously 
Table 1 | Differences and commonalities in hormone defense networking in rice and Arabidopsis.

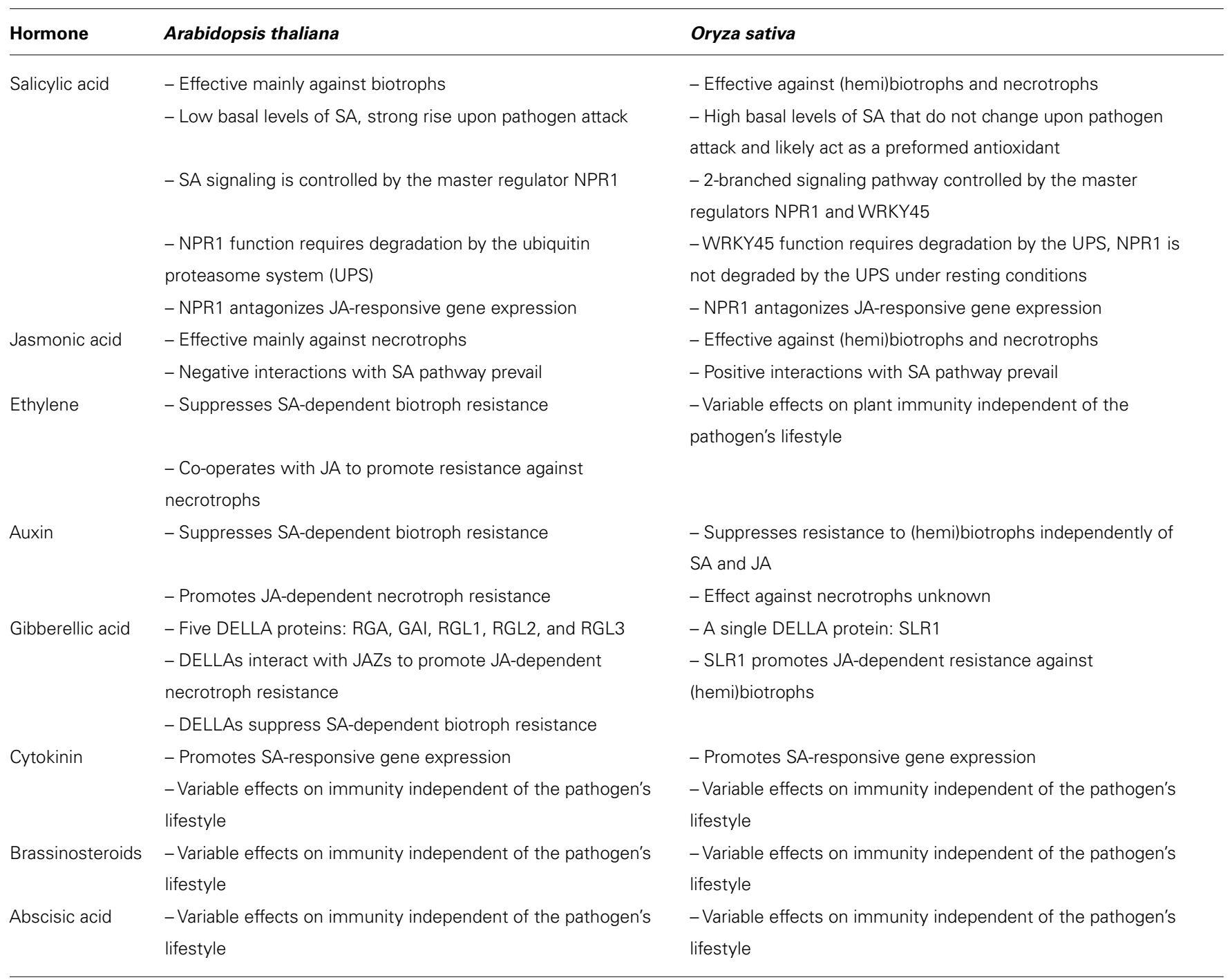

administered GA, suggesting reciprocal synergism between the JA and SLR1 signaling pathways (Yang et al., 2012). Considering that many other hormones affect DELLA protein stability, either directly or indirectly, it thus seems that SLR1 is positioned at the intersection of various hormone pathways, acting as a main hub for signal crosstalk and pathway integration (De Bruyne et al., 2014).

\section{TIME FOR ACTION: TOWARD ENGINEERING HORMONE-BASED SUSTAINABLE DISEASE RESISTANCE IN RICE}

The past decade has seen tremendous progress in understanding hormone perception and signaling in rice and its role in molding pathological outcomes. Although far from complete, our knowledge of the rice defense signaling network may now be detailed enough to contemplate the rational deployment of it for engineering disease-resistant rice plants.

To date, most translational efforts have focused on reinforcing rice defense signaling by transgenic manipulation of hormone signaling components. Given its strong impact on resistance against the hemibiotrophs Magnaporthe oryzae and Xoo and its ability to reduce susceptibility against the necrotrophic root pathogens Pythium graminicola and Hirschmanniella oryzae, SA regulatory elements are ideal candidates for engineering broadspectrum disease resistance in rice. Unfortunately, the disease resistance governed by constitutive overexpression or knockout of positive and negative regulators of the SA pathway, respectively, is most often accompanied by severe growth defects and/or impaired tolerance to abiotic stresses. Thus, various groups have shown that high-level expression of OsNPR1 and OsWRKY45 results in strong growth retardation and formation of lesion-mimics, while transgenic rice lines overexpressing OsWRKY13 are hypersensitive to drought (Chern et al., 2005; Shimono et al., 2007; Xiao et al., 2013). These negative effects, commonly referred to as tradeoffs, are attributed to the reallocation of resources from growth to defense against the most life-threatening stress and must be overcome to maximize rice yield under variable environmental conditions (Sharma et al., 2013; Huot et al., 2014). 


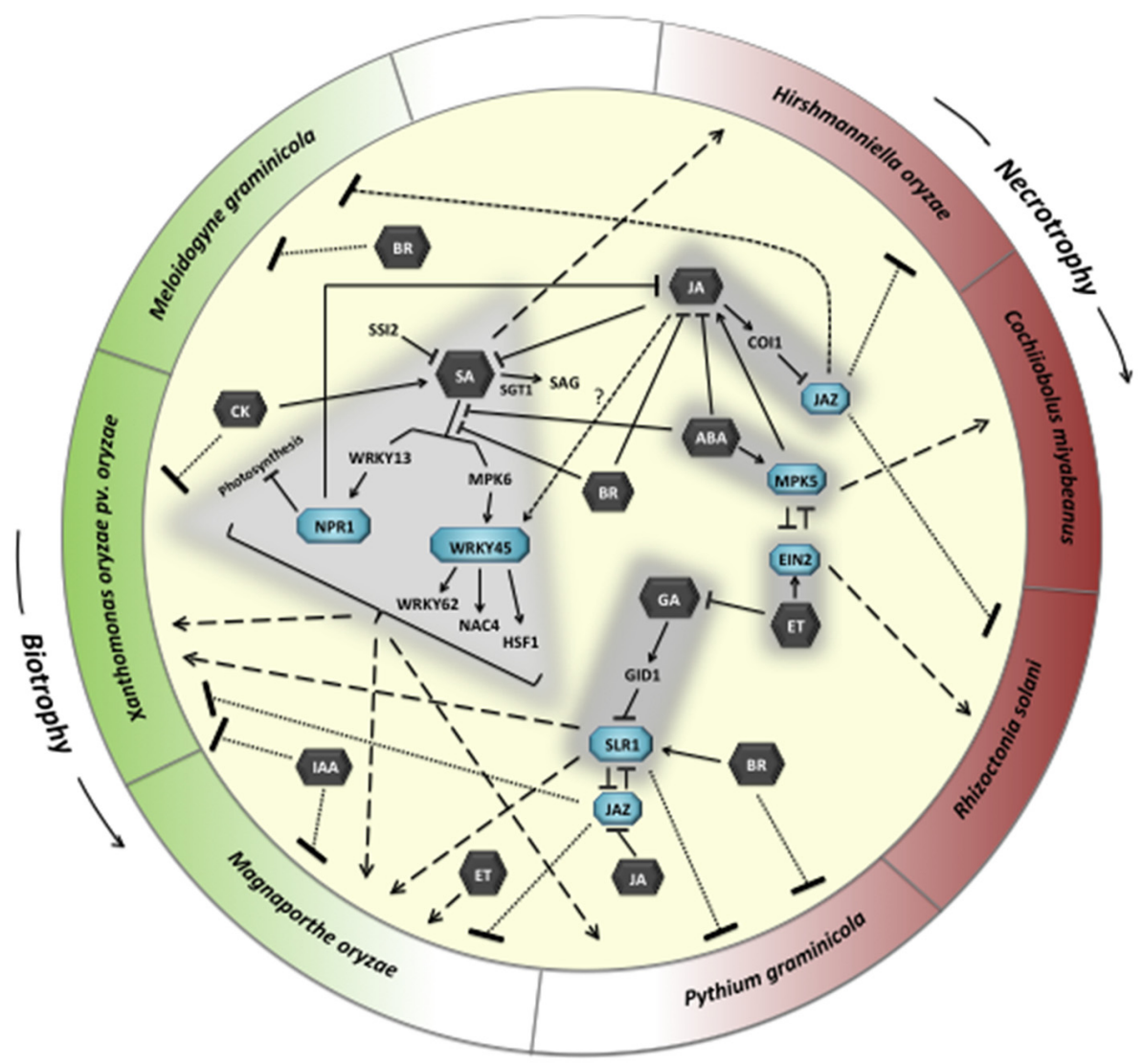

FIGURE 1 | Model illustrating the role of hormone signaling pathways and their crosstalk in molding disease outcomes in rice. Sharp arrows indicate positive effects, blunt-ended lines depict negative effects. SA, salicylic acid; JA, jasmonic acid; ET, ethylene; ABA, abscisic acid; CK, cytokinin; IAA, auxin; GA, gibberellic acid; BR, brassinosteroids.

One approach to bypass trade-offs is by managing the expression level of the transgene. Recent findings revealed that moderate expression of OsWRKY45 under control of a weak constitutive promoter largely eliminated the fitness costs and environmental sensitivity related to strong OsWRKY45 expression, while retaining disease resistance (Takatsuji and Jiang, 2014). Similarly, low-level silencing of OsSSI2, a negative regulator of the rice SA pathway, resulted in strong resistance to Magnaporthe oryzae and Xoo without appreciable growth defects, whereas OsSSI2 knockout plants were severely stunted (Jiang et al., 2009). The use of highly specific pathogen-inducible promoters is an additional strategy to finetune the location, timing and magnitude of transgene expression. To avoid spurious defense activation, ideal candidate promoters are those that are not PAMP responsive but are rapidly induced by virulent pathogens (Grant et al., 2013). Although relatively few effector-responsive rice genes have been identified thus far, the increasing availability of high temporal microarray data of a range of rice-pathogen interactions may open the door to identifying tightly controlled transcriptional units that can be used to drive transgene expression when and where pathogens invade.

In addition, trade-offs may be circumvented by engineering transgenic rice lines that are designed to neutralize microbial hormone intervention strategies. Such proactive response necessitates the identification and precision engineering of core pathogenmodulated hormone signaling elements and re-wiring these components to promoters specifying precise, temporally and spatially controlled responses to pathogens (Grant et al., 2013). Interfering with hormone-based virulence strategies seems especially promising for pathogens such as Xoo and Magnaporthe oryzae which are thought to hijack the rice ABA, auxin, and GA pathways to induce host susceptibility (see above).

To prevent microbial manipulation of these pathways, one could envisage creating a dominant hormone-insensitive phenotype, either via local and timely disruption of hormone perception or through ectopic expression of re-engineered negative regulators of hormone signaling such as ABA-repressing Clade A protein phosphatase 2Cs (PP2C). Upon ABA binding, a family of cytosolic ABA receptors commonly known as PYLs (PYRABACTIN RESISTANCE LIKE) bind to and inhibit the active site of PP2Cs. This alleviates negative regulation on the PP2C target sucrose nonfermenting related kinase 2 (SnRK2), leading to activation of ABA signaling (Cutler et al., 2010; Weiner et al., 2010). Interestingly, mutations of specific residues residing in the active site of PP2Cs disrupt PYL-PP2C interactions but retain the ability to dephosphorylate target SnRK2s (Miyazono et al., 2009; Melcher et al., 2010). Driving the expression of such mutated PP2Cs may 
thus inactivate ABA signaling at two key nodes (Grant et al., 2013).

A similar strategy could be followed for SLR1 and Aux/IAA proteins, which function as the central repressors of GA and auxin signaling, respectively. Upon hormone perception, these negative regulators are targeted by cognate F-box proteins for polyubiquitination and subsequently degraded by the $26 \mathrm{~S}$ proteasome, thus relieving their repressive effect. Structural and predictive modeling have revealed the domains and residues involved in SLR1 and Aux/IAA protein-protein interactions (Gray et al., 2001; Hirano et al., 2010; Sato et al., 2014). Therefore, one may consider rewiring engineered SLR1 and Aux/IAA variants that no longer bind the corresponding F-box proteins GID2 and TIR1 and, hence, are resistant to UPS-mediated degradation. In a dual approach that complements the re-wiring of hormone signaling pathways, it would also be possible to alleviate pathogen-induced hormone accumulation by connecting well-characterized hormone catabolism genes such as ABA 8'-hydroxylases, GA 2-oxidases or auxin-inducible GH3 enzymes to pathogen-responsive promoters (Saika etal., 2007; Lo etal., 2008; Jain and Khurana, 2009).

\section{CONCLUDING REMARKS}

Over the past decade, significant inroads have been made in our understanding of hormone defense signaling in Arabidopsis and other dicot plants. However, as illustrated throughout this review, the conceptual framework emerging from these studies does not always translate to monocot systems (Table 1). While underscoring the importance of using alternative models systems, the unique complexities associated with defense networking in rice call for a re-evaluation of overly generalized defense models.

Contrary to the classic binary defense model with SA and JA playing opposite roles in biotroph and necrotroph resistance, respectively, innate immunity in rice appears to be controlled by a much more complicated signaling network that supports no clear dichotomy between the effectiveness of most hormone pathways and the overall infection biology of the invading pathogen (Figure 1). Most conspicuously, although hyperactivation of one can attenuate the other, synergistic SA-JA interactions seem to prevail in rice and the two hormones are effective against both hemibiotrophic and necrotrophic rice pathogens. Moreover, unlike in dicots, we are unaware of any reports showing negative effects of SA or JA on rice pathogen defenses. Therefore, it is not inconceivable that both hormones function as endogenous priming agents that amplify infection-induced defense reactions regardless of the lifestyle of the invading pathogen. In contrast, ET can have both positive and negative effects on rice disease resistance that are seemingly independent of the pathogen's parasitic habits.

The impact of developmental hormones is equally complex. As was reported in Arabidopsis, auxin promotes susceptibility to (hemi)biotrophic rice pathogens, while CK signaling can cascade either to the detriment or the benefit of plant. GAs, on the other hand, appear to play opposite roles in rice and Arabidopsis. Finally and consistent with their ambivalent role in dicot immunity, BRs and $\mathrm{ABA}$ can both promote and suppress rice immunity depending not only on the type of pathogen, but also on the type of tissue, and even spatial and temporal conditions.

Despite the recent progress, much remains to be learned about the role of hormones in the regulation of the rice defense signaling network. For instance, it is still unclear how SA and JA are perceived in rice and how their signaling pathways interact at the molecular level, there is little information available about the impact of viruses, insects and nematodes on the rice hormone signaling network, and there is still much to be learned about the hormone intervention strategies used by rice pathogens to inflict disease. Moreover, few studies have investigated the spatiotemporal dynamics of a given hormone during rice-pathogen interactions and none addresses the kinetics and signature of the blend of hormones released upon pathogen attack. Finally, there is a paucity of knowledge on the molecular players orchestrating pathway crosstalk and signal integration in the rice signaling circuitry. Deepening our knowledge in this area is especially important since defining synergies and trade-offs may help identify appropriate contexts for the optimal deployment and commercial acceptance of hormone-based rice disease resistance.

\section{ACKNOWLEDGMENTS}

We apologize to colleagues whose work could not be cited owing to space limitations. This work was supported by a $\mathrm{PhD}$ scholarship of the Chinese Research Council given to Jing $\mathrm{Xu}$, grants from the Special Research Fund of Ghent University (GOA 01GB3013), the Research Foundation Flanders (FWO, project G.0833.12N), and a FWO postdoctoral fellowship to David De Vleesschauwer.

\section{REFERENCES}

Adie, B. A., Pérez-Pérez, J., Pérez-Pérez, M. M., Godoy, M., Sánchez-Serrano, J. J., Schmelz, E. A., et al. (2007). ABA is an essential signal for plant resistance to pathogens affecting JA biosynthesis and the activation of defenses in Arabidopsis. Plant Cell 19, 1665-1681. doi: 10.1105/tpc.106.048041

Akagi, A., Fukushima, S., Okada, K., Jiang, C. J., Yoshida, R., Nakayama, A., et al. (2014). WRKY45-dependent priming of diterpenoid phytoalexin biosynthesis in rice and the role of cytokinin in triggering the reaction. Plant Mol. Biol. 86, 171-183. doi: 10.1007/s11103-014-0221-x

Albrecht, C., Boutrot, F., Segonzac, C., Schwessinger, B., Gimenez-Ibanez, S., Chinchilla, D., et al. (2012). Brassinosteroids inhibit pathogen-associated molecular pattern-triggered immune signaling independent of the receptor kinase BAK1. Proc. Natl. Acad. Sci. U.S.A. 109, 303-308. doi: 10.1073/pnas.1109921108

Argueso, C. T., Ferreira, F. J., Epple, P., To, J. P. C., Hutchison, C. E., Schaller, G. E., etal. (2012). Two-component elements mediate interactions between cytokinin and salicylic acid in plant immunity. PLoS Genet. 8:e1002448. doi: 10.1371/journal.pgen.1002448

Asselbergh, B., De Vleesschauwer, D., and Höfte, M. (2008). Global switches and fine-tuning: ABA modulates plant pathogen defense. Mol. Plant Microbe Interact. 21, 709-719. doi: 10.1094/Mpmi-21-6-0709

Bailey, T. A., Zhou, X. J., Chen, J. P., and Yang, Y. (2009). "Role of ethylene, abscisic acid and MAP kinase pathways in rice blast resistance," in Advances in Genetics, Genomics and Control of Rice Blast Disease, eds G. L. Wang and B. Valent (Dordrecht: Springer Science), 185-190. doi: 10.1007/978-1-4020-9500-9_19

Bari, R., and Jones, J. (2009). Role of plant hormones in plant defence responses. Plant Mol. Biol. 69, 473-488. doi: 10.1007/s11103-008-9435-0

Belkhadir, Y., Jaillais, Y., Epple, P., Balsemão-Pires, E., Dangl, J. L., Chory, J., et al. (2012). Brassinosteroids modulate the efficiency of plant immune responses to microbe-associated molecular patterns. Proc. Natl. Acad. Sci. U.S.A. 109, 297-302. doi: 10.1073/pnas.1112840108

Boatwright, J. L., and Pajerowska-Mukhtar, K. (2013). Salicylic acid: an old hormone up to new tricks. Mol. Plant Pathol. 14, 623-634. doi: 10.1111/mpp.12035

Boller, T., and Felix, G. (2009). A renaissance of elicitors: perception of microbe-associated molecular patterns and danger signals by pattern-recognition 
receptors. Annu. Rev. Plant Biol. 60, 379-406. doi: 10.1146/annurev.arplant. 57.032905 .105346

Bostock, R. M. (2005). Signal crosstalk and induced resistance: straddling the line between cost and benefit. Annu. Rev. Phytopathol. 43, 545-580. doi: 10.1146/annurev.phyto.41.052002.095505

Cao, F., Yoshioka, K., and Desveaux, D. (2011). The roles of ABA in plant-pathogen interactions. J. Plant Res. 124, 489-499. doi: 10.1007/s10265-011-0409-y

Cao, H., Li, X., and Dong, X. N. (1998). Generation of broad-spectrum disease resistance by overexpression of an essential regulatory gene in systemic acquired resistance. Proc. Natl. Acad. Sci. U.S.A. 95, 6531-6536. doi: 10.1073/pnas.95.11.6531

Chen, X., and Ronald, P. C. (2011). Innate immunity in rice. Trends Plant Sci. 16, 451-459. doi: 10.1016/j.tplants.2011.04.003

Cheng, Y. T., Germain, H., Wiermer, M., Bi, D., Xu, F., Garcia, A. V., et al. (2009). Nuclear pore complex component MOS7/Nup88 is required for innate immunity and nuclear accumulation of defense regulators in Arabidopsis. Plant Cell 21, 2503-2516. doi: 10.1105/tpc.108.064519

Chern, M., Fitzgerald, H. A., Canlas, P. E., Navarre, D. A., and Ronald, P. C. (2005). Overexpression of a rice NPR1 homolog leads to constitutive activation of defense response and hypersensitivity to light. Mol. Plant Microbe Interact. 18, 511-520. doi: 10.1094/MPMI-18-0511

Choi, J., Choi, D., Lee, S., Ryu, C. M., and Hwang, I. (2011). Cytokinins and plant immunity: old foes or new friends? Trends Plant Sci. 16, 388-394. doi: 10.1016/j.tplants.2011.03.003

Choi, J., Huh, S. U., Kojima, M., Sakakibara, H., Paek, K. H., and Hwang, I. (2010) The cytokinin-activated transcription factor ARR2 promotes plant immunity via TGA3/NPR1-dependent salicylic acid signaling in Arabidopsis. Dev. Cell 19, 284-295. doi: 10.1016/j.devcel.2010.07.011

Clarke, J. D., Liu, Y. D., Klessig, D. F., and Dong, X. N. (1998). Uncoupling PR gene expression from NPR1 and bacterial resistance: characterization of the dominant Arabidopsis cpr6-1 mutant. Plant Cell 10, 557-569.

Clarke, J. D., Volko, S. M., Ledford, H., Ausubel, F. M., and Dong, X. N. (2000). Roles of salicylic acid, jasmonic acid, and ethylene in cpr-induced resistance in Arabidopsis. Plant Cell 12, 2175-2190. doi: 10.1105/tpc.12.11.2175

Clarke, S. M., Cristescu, S. M., Miersch, O., Harren, F. J. M., Wasternack, C., and Mur, L. A. J. (2009). Jasmonates act with salicylic acid to confer basal thermotolerance in Arabidopsis thaliana. New Phytol. 182, 175-187. doi 10.1111/j.1469-8137.2008.02735.x

Cutler, S. R., Rodriguez, P. L., Finkelstein, R. R., and Abrams, S. R. (2010). Abscisic acid: emergence of a core signaling network. Annu. Rev. Plant Biol. 61, 651-679. doi: 10.1146/annurev-arplant-042809-112122

De Bruyne, L., Höfte, M., and De Vleesschauwer, D. (2014). Connecting growth and defense: the emerging roles of brassinosteroids and gibberellins in plant immunity. Mol. Plant. 7, 943-959. doi: 10.1093/mp/ssu050

Derksen, H., Rampitsch, C., and Daayf, F. (2013). Signaling cross-talk in plant disease resistance. Plant Sci. 207, 79-87. doi: 10.1016/j.plantsci.2013.03.004

de Torres-Zabala, M., Bennett, M. H., Truman, W. H., and Grant, M. R. (2009). Antagonism between salicylic and abscisic acid reflects early hostpathogen conflict and moulds plant defence responses. Plant J. 59, 375-386. doi: 10.1111/j.1365-313X.2009.03875.x

de Torres-Zabala, M., Truman, W., Bennett, M. H., Lafforgue, G., Mansfield, J. W., Rodriguez Egea, P., et al. (2007). Pseudomonas syringae pv. tomato hijacks the Arabidopsis abscisic acid signalling pathway to cause disease. EMBO J. 26, 1434 1443. doi: 10.1038/sj.emboj.7601575

Devadas, S. K., Enyedi, A., and Raina, R. (2002). The Arabidopsis hrll mutation reveals novel overlapping roles for salicylic acid, jasmonic acid and ethylene signalling in cell death and defence against pathogens. Plant J. 30, 467-480. doi: 10.1046/j.1365-313X.2002.01300.x

De Vleesschauwer, D., Djavaheri, M., Bakker, P. A., and Höfte, M. (2008) Pseudomonas fluorescens WCS374r-induced systemic resistance in rice against Magnaporthe oryzae is based on pseudobactin-mediated priming for a salicylic acid-repressible multifaceted defense response. Plant Physiol. 148, 1996-2012. doi: 10.1104/pp.108.127878

De Vleesschauwer, D., Gheysen, G., and Höfte, M. (2013). Hormone defense networking in rice: tales from a different world. Trends Plant Sci. 18, 555-565. doi: 10.1016/j.tplants.2013.07.002

De Vleesschauwer, D., Van Buyten, E., Satoh, K., Balidion, J., Mauleon, R., Choi, I. R., et al. (2012). Brassinosteroids antagonize gibberellin- and salicylate-mediated root immunity in rice. Plant Physiol. 158, 1833-1846. doi: 10.1104/pp.112. 193672

De Vleesschauwer, D., Yang, Y. N., Cruz, C. V., and Höfte, M. (2010). Abscisic acidinduced resistance against the brown spot pathogen Cochliobolus miyabeanus in rice involves MAP kinase-mediated repression of ethylene signaling. Plant Physiol. 152, 2036-2052. doi: 10.1104/pp.109.152702

De Vos, M., Van Oosten, V. R., Van Poecke, R. M. P., Van Pelt, J. A., Pozo, M. J., Mueller, M. J., et al. (2005). Signal signature and transcriptome changes of Arabidopsis during pathogen and insect attack. Mol. Plant Microbe Interact. 18, 923-937. doi: 10.1094/mpmi-18-0923

Ding, X., Cao, Y., Huang, L., Zhao, J., Xu, C., Li, X., et al. (2008). Activation of the indole-3-acetic acid amido synthetase GH3-8 suppresses expansin expression and promotes salicylate- and jasmonate-independent basal immunity in rice. Plant Cell 20, 228-240. doi: 10.1105/tpc.107.055657

Divi, U. K., Rahman, T., and Krishna, P. (2010). Brassinosteroid-mediated stress tolerance in Arabidopsis shows interactions with abscisic acid, ethylene and salicylic acid pathways. BMC Plant Biol. 10:151-164. doi: 10.1186/1471-222910-151

Domingo, C., Andrés, F., Tharreau, D., Iglesias, D. J., and Talón, M. (2009). Constitutive expression of OsGH3.1 reduces auxin content and enhances defense response and resistance to a fungal pathogen in rice. Mol. Plant Microbe Interact. 22, 201-210. doi: 10.1094/MPMI-22-2-0201

Du, H., Wu, N., Fu, J., Wang, S., Li, X., Xiao, J., et al. (2012). A GH3 family member, OsGH3-2, modulates auxin and abscisic acid levels and differentially affects drought and cold tolerance. J. Exp. Bot. 63, 695-709. doi: 10.1093/jxb/err313

Feys, B. J., Moisan, L. J., Newman, M. A., and Parker, J. E. (2001). Direct interaction between the Arabidopsis disease resistance signaling proteins, EDS1 and PAD4. EMBO J. 20, 5400-5411. doi: 10.1093/emboj/20.19.5400

Fitzgerald, H. A., Chern, M. S., Navarre, R., and Ronald, P. C. (2004). Overexpression of (At)NPR1 in rice leads to a BTH- and environment-induced lesion-mimic/cell death phenotype. Mol. Plant Microbe Interact. 17, 140-151. doi: 10.1094/MPMI.2004.17.2.140

Fu, J., Liu, H. B., Li, Y., Yu, H. H., Li, X. H., Xiao, J. H., et al. (2011). Manipulating broad-spectrum disease resistance by suppressing pathogen-induced auxin accumulation in rice. Plant Physiol. 155, 589-602. doi: 10.1104/pp.110.163774.

$\mathrm{Fu}$, J., and Wang, S. (2011). Insights into auxin signaling in plant-pathogen interactions. Front. Plant Sci. 2:1-7. doi: 10.3389/fpls.2011.00074

Fu, Z. Q., Yan, S., Saleh, A., Wang, W., Ruble, J., Oka, N., et al. (2012). NPR3 and NPR4 are receptors for the immune signal salicylic acid in plants. Nature 486, 228-232. doi: 10.1038/nature 11162

Garg, R., Tyagi, A. K., and Jain, M. (2012). Microarray analysis reveals overlapping and specific transcriptional responses to different plant hormones in rice. Plant Signal. Behav. 7, 951-956. doi: 10.4161/psb.20910

Glazebrook, J. (2005). Contrasting mechanisms of defense against biotrophic and necrotrophic pathogens. Annu. Rev. Phytopathol. 43, 205-227. doi: 10.1146/annurev.phyto.43.040204.135923

Glazebrook, J., Chen, W. J., Estes, B., Chang, H. S., Nawrath, C., Metraux, J. P., et al. (2003). Topology of the network integrating salicylate and jasmonate signal transduction derived from global expression phenotyping. Plant J. 34, 217-228. doi: 10.1046/j.1365-313X.2003.01717.x

Goel, A. K., Lundberg, D., Torres, M. A., Matthews, R., Akimoto, T. C., Farmer, L., et al. (2008). The Pseudomonas syringae type III effector HopAM1 enhances virulence on water-stressed plants. Mol. Plant Microbe Interact. 21, 361-370. doi: 10.1094/mpmi-21-3-0361

González-Lamothe, R., El Oirdi, M., Brisson, N., and Bouarab, K. (2012). The conjugated auxin indole-3-acetic acid-aspartic acid promotes plant disease development. Plant Cell 24, 762-777. doi: 10.1105/tpc.111.095190

Grant, M. R., and Jones, J. D. G. (2009). Hormone (dis)harmony moulds plant health and disease. Science 324, 750-752. doi: 10.1126/science.1173771

Grant, M. R., Kazan, K., and Manners, J. M. (2013). Exploiting pathogens' tricks of the trade for engineering of plant disease resistance: challenges and opportunities. Microb. Biotechnol. 6, 212-222. doi: 10.1111/1751-7915.12017

Gray, W. M., Kepinski, S., Rouse, D., Leyser, O., and Estelle, M. (2001). Auxin regulates SCFTIR1-dependent degradation of AUX/IAA proteins. Nature 414, 271-276. doi: 10.1038/35104500

Grosskinsky, D. K., Naseem, M., Ramadan Abdelmohsen, U., Plickert, N., Engelke, T., Griebel, T., et al. (2011). Cytokinins mediate resistance against Pseudomonas syringae in tobacco through increased antimicrobial phytoalexin 
synthesis independent of salicylic acid signalling. Plant Physiol. 57, 815-830. doi: 10.1104/pp.111.182931

Hann, D. R., Dominguez-Ferreras, A., Motyka, V., Dobrev, P. I., Schornack, S., Jehle, A., et al. (2014). The Pseudomonas type III effector HopQ1 activates cytokinin signaling and interferes with plant innate immunity. New Phytol. 201, 585-598. doi: $10.1111 /$ nph. 12544

Hayashi, S., Wakasa, Y., and Takaiwa, F. (2012). Functional integration between defence and IRE1-mediated ER stress response in rice. Sci. Rep. 2, 670. doi: $10.1038 /$ srep00670

Hilpert, B., Bohlmann, H., op den Camp, R., Przybyla, D., Miersch, O., Buchala, A., et al. (2001). Isolation and characterization of signal transduction mutants of Arabidopsis thaliana that constitutively activate the octadecanoid pathway and form necrotic microlesions. Plant J. 26, 435-446. doi: 10.1046/j.1365313X.2001.2641036.x

Hirano, K., Asano, K., Tsuji, H., Kawamura, M., Mori, H., Kitano, H., et al. (2010) Characterization of the molecular mechanism underlying gibberellin perception complex formation in rice. Plant Cell 22, 2680-2696. doi: 10.1105/tpc.110. 075549

Ho, Y. P., Tan, C. M., Li, M. Y., Lin, H., Deng, W. L., and Yang, J. Y. (2013) The AvrB_AvrC domain of AvrXccC of Xanthomonas campestris pv. campestris is required to elicit plant defense responses and manipulate ABA homeostasis. Mol. Plant Microbe Interact. 26, 419-430. doi: 10.1094/mpmi-06-120164-r

Hou, X., Lee, L. Y. C., Xia, K., Yan, Y., and Yu, H. (2010). DELLAs modulate jasmonate signaling via competitive binding to JAZs. Dev. Cell 19, 884-894. doi: 10.1016/j.devcel.2010.10.024

Huot, B., Yao, J., Montgomery, B. L., and He, S. Y. (2014). Growth-defense tradeoffs in plants: a balancing act to optimize fitness. Mol. Plant 7, 1267-1287. doi $10.1093 / \mathrm{mp} / \mathrm{ssu} 049$

Inoue, H., Hayashi, N., Matsushita, A., Xinqiong, L., Nakayama, A., Sugano, S. et al. (2013). Blast resistance of CC-NB-LRR protein Pbl is mediated by WRKY45 through protein-protein interaction. Proc. Natl. Acad. Sci. U.S.A. 110, 9577-9582. doi: 10.1073/pnas. 1222155110

Iwai, T., Seo, S., Mitsuhara, I., and Ohashi, Y. (2007). Probenazole-induced accumulation of salicylic acid confers resistance to Magnaporthe grisea in adult rice plants. Plant Cell Physiol. 48, 915-924. doi: 10.1093/pcp/pcm062

Jain, M., and Khurana, J. P. (2009). Transcript profiling reveals diverse roles of auxin-responsive genes during reproductive development and abiotic stress in rice. FEBS J. 276, 3148-3162. doi: 10.1111/j.1742-4658.2009. 07033.x

Jiang, C. J., Shimono, M., Maeda, S., Inoue, H., Mori, M., Hasegawa, M., et al. (2009). Suppression of the rice fatty-acid desaturase gene OsSSI2 enhances resistance to blast and leaf blight diseases in rice. Mol. Plant Microbe Interact. 22, 820-829. doi: 10.1094/MPMI-22-7-0820

Jiang, C. J., Shimono, M., Sugano, S., Kojima, M., Liu, X. Q., Inoue, H., et al. (2013). Cytokinins act synergistically with salicylic acid to activate defense gene expression in rice. Mol. Plant Microbe Interact. 26, 287-296. doi: 10.1094/mpmi06-12-0152-r

Jiang, C. J., Shimono, M., Sugano, S., Kojima, M., Yazawa, K., Yoshida, R., et al. (2010). Abscisic acid interacts antagonistically with salicylic acid signaling pathway in rice-Magnaporthe grisea interaction. Mol. Plant Microbe Interact. 23, 791-798. doi: 10.1094/mpmi-23-6-0791

Jirage, D., Tootle, T. L., Reuber, T. L., Frost, L. N., Feys, B. J., Parker, J. E., et al. (1999). Arabidopsis thaliana PAD4 encodes a lipase-like gene that is important for salicylic acid signaling. Proc. Natl. Acad. Sci. U.S.A. 96, 13583-13588. doi: 10.1073/pnas.96.23.13583

Jones, J. D. G., and Dangl, J. L. (2006). The plant immune system. Nature 444, 323-329. doi: 10.1038/nature05286

Jung, K. H., An, G., and Ronald, P. C. (2008). Towards a better bowl of rice: assigning function to tens of thousands of rice genes. Nat. Rev. Genet. 9, 91-101. doi: $10.1038 / \operatorname{nrg} 2286$

Kankanala, P., Czymmek, K., and Valent, B. (2007). Roles for rice membrane dynamics and plasmodesmata during biotrophic invasion by the blast fungus. Plant Cell 19, 706-724. doi: 10.1105/tpc.106.046300

Kazan, K., and Manners, J. M. (2012). JAZ repressors and the orchestration of phytohormone crosstalk. Trends Plant Sci. 17, 22-31. doi: 10.1016/j.tplants.2011.10.006

Kazan, K., and Manners, J. M. (2013). MYC2: the master in action. Mol. Plant 6 , 686-703. doi: $10.1093 / \mathrm{mp} / \mathrm{sss} 128$
Ke, Y., Liu, H., Li, X., Xiao, J., and Wang, S. (2014). Rice OsPAD4 functions differently from Arabidopsis AtPAD4 in host-pathogen interactions. Plant J. 78, 619-631. doi: 10.1111/tpj.12500

Kyndt, T., Fernandez, D., and Gheysen, G. (2014). Plant-parasitic nematode infections in rice: molecular and cellular insights. Annu. Rev. Phythopathol. 52, 135-153. doi: 10.1146/annurev-phyto-102313-050111

Lee, A., Cho, K., Jang, S., Rakwal, R., Iwahashi, H., Agrawal, G. K., et al. (2004). Inverse correlation between jasmonic acid and salicylic acid during early wound response in rice. Biochem. Biophys. Res. Commun. 318, 734-738. doi: 10.1016/j.bbrc.2004.04.095

Lee, M. W., Qi, M., and Yang, Y. (2001). A novel jasmonic acid-inducible rice myb gene associates with fungal infection and host cell death. Mol. Plant Microbe Interact. 14, 527-535. doi: 10.1094/MPMI.2001.14.4.527

Li, R., Afsheen, S., Xin, Z., Han, X., and Lou, Y. (2013). OsNPR1 negatively regulates herbivore-induced JA and ethylene signaling and plant resistance to a chewing herbivore in rice. Physiol. Plant. 147, 340-351. doi: 10.1111/j.13993054.2012.01666.x

Lipka, V., Dittgen, J., Bednarek, P., Bhat, R., Wiermer, M., Stein, M., et al. (2005). Preand postinvasion defenses both contribute to nonhost resistance in Arabidopsis. Science 310, 1180-1183. doi: 10.1126/science.1119409

Liu, H., Li, X., Xiao, J., and Wang, S. (2012a). A convenient method for simultaneous quantification of multiple phytohormones and metabolites: application in study of rice-bacterium interaction. Plant Methods 8, 2-13. doi: 10.1186/17464811-8-2

Liu, X., Li, F., Tang, J., Wang, W., Zhang, F., Wang, G., et al. (2012b). Activation of the jasmonic acid pathway by depletion of the hydroperoxide lyase OsHPL3 reveals crosstalk between the HPL and AOS branches of the oxylipin pathway in rice. PLOS ONE 7:e50089. doi: 10.1371/journal.pone.0050089

Liu, W., Liu, J., Ning, Y., Ding, B., Wang, X., Wang, Z., et al. (2013a). Recent progress in understanding PAMP- and effector-triggered immunity against the rice blast fungus Magnaporthe oryzae. Mol. Plant 6, 605-620. doi: 10.1093/mp/sst015

Liu, Z., Wu, Y., Yang, F., Zhang, Y., Chen, S., Xie, Q., et al. (2013b). BIK1 interacts with PEPRs to mediate ethylene-induced immunity. Proc. Natl. Acad. Sci. U.S.A. 110, 6205-6210. doi: 10.1073/pnas.1215543110

Llorente, F., Muskett, P., Sánchez-Vallet, A., López, G., Ramos, B., and SánchezRodríguez, et al. (2008). Repression of the auxin response pathway increases Arabidopsis susceptibility to necrotrophic fungi. Mol. Plant 1, 496-509. doi: $10.1093 / \mathrm{mp} / \mathrm{ssn} 025$

Lo, S. F., Yang, S. Y., Chen, K. T., Hsing, Y. l., Zeevaart, J. A. D., Chen, L. J., et al. (2008). A novel class of gibberellin 2-oxidases control semidwarfism, tillering, and root development in rice. Plant Cell 20, 2603-2618. doi: 10.1105/tpc.108.060913

Lozano-Durán, R., Macho, A. P., Boutrot, F., Segonzac, C., Somssich, I. E., and Zipfel, C. (2013). The transcriptional regulator BZR1 mediates trade-off between plant innate immunity and growth. Elife 2:e00983. doi: 10.7554/eLife.00983

Lu, J., Li, J., Ju, H., Liu, X., Erb, M., Wang, X., et al. (2014). Contrasting effects of ethylene biosynthesis on induced plant resistance against a chewing and a piercing-sucking herbivore in rice. Mol. Plant doi: 10.1093/mp/ssu085 [Epub ahead of print].

Macho, A. P., and Zipfel, C. (2014). Plant PRRs and the activation of innate immune signaling. Mol. Cell 54, 263-272. doi: 10.1016/j.molcel.2014.03.028

Malamy, J., and Klessig, D. F. (1992). Salicylic acid and plant disease resistance. Plant J. 2, 643-654. doi: 10.1111/j.1365-313X.1992.tb00133.x

Matsushita, A., Inoue, H., Goto, S., Nakayama, A., Sugano, S., Hayashi, N., et al. (2013). The nuclear ubiquitin proteasome degradation affects WRKY45 function in the rice defense program. Plant J. 73, 302-313. doi: 10.1111/tpj.12035

Mei, C., Qi, M., Sheng, G., and Yang, Y. (2006). Inducible overexpression of a rice allene oxide synthase gene increases the endogenous jasmonic acid level, PR gene expression, and host resistance to fungal infection. Mol. Plant Microbe Interact. 19, 1127-1137. doi: 10.1094/MPMI-19-1127

Melcher, K., Xu, Y., Ng, L. M., Zhou, X. E., Soon, F. F., Chinnusamy, V., et al. (2010). Identification and mechanism of ABA receptor antagonism. Nat. Struct. Mol. Biol. 17, 1102-1110. doi: 10.1038/nsmb.1887

Melotto, M., Underwood, W., Koczan, J., Nomura, K., and He, S. Y. (2006). Plant stomata function in innate immunity against bacterial invasion. Cell 126, 969980. doi: 10.1016/j.cell.2006.06.054

Metraux, J. P., Signer, H., Ryals, J., Ward, E., Wyssbenz, M., Gaudin, J., et al. (1990). Increase in salicylic acid at the onset of systemic acquired resistance in cucumber. Science 250, 1004-1006. doi: 10.1126/science.250.4983.1004 
Mishina, T. E., and Zeier, J. (2007). Pathogen-associated molecular pattern recognition rather than development of tissue necrosis contributes to bacterial induction of systemic acquired resistance in Arabidopsis. Plant J. 50, 500-513. doi: 10.1111/j.1365-313X.2007.03067.x

Miyazono, K. I., Miyakawa, T., Sawano, Y., Kubota, K., Kang, H. J., Asano, A., et al (2009). Structural basis of abscisic acid signalling. Nature 462, 609-614. doi 10.1038 /nature08583

Mohr, P., and Cahill, D. (2007). Suppression by ABA of salicylic acid and lignin accumulation and the expression of multiple genes, in Arabidopsis infected with Pseudomonas syringae pv. tomato. Funct. Integr. Genomics 7, 181-191. doi: 10.1007/s10142-006-0041-4

Mur, L. A. J., Kenton, P., Atzorn, R., Miersch, O., and Wasternack, C. (2006). The outcomes of concentration-specific interactions between salicylate and jasmonate signaling include synergy, antagonism, and oxidative stress leading to cell death. Plant Physiol. 140, 249-262. doi: 10.1104/pp.105.072348

Mutka, A. M., Fawley, S., Tsao, T., and Kunkel, B. N. (2013). Auxin promotes susceptibility to Pseudomonas syringae via a mechanism independent of suppression of salicylic acid-mediated defenses. Plant J. 74, 746-754. doi: 10.1111/tpj. 12157

Nahar, K., Kyndt, T., De Vleesschauwer, D., Höfte, M., and Gheysen, G. (2011) The jasmonate pathway is a key player in systemically induced defense against root knot nematodes in rice. Plant Physiol. 157, 305-316. doi: 10.1104/pp.111. 177576

Nahar, K., Kyndt, T., Hause, B., Höfte, M., and Gheysen, G. (2013). Brassinosteroids suppress rice defense against root-knot nematodes through antagonism with the jasmonate pathway. Mol. Plant Microbe Interact. 26, 106-115. doi: 10.1094/MPMI-05-12-0108-FI

Nahar, K., Kyndt, T., Nzogela, Y. B., and Gheysen, G. (2012). Abscisic acid interacts antagonistically with classical defense pathways in rice-migratory nematode interaction. New Phytol. 196, 901-913. doi: 10.1111/j.1469-8137.2012. 04310.x

Nakashita, H., Yasuda, M., Nitta, T., Asami, T., Fujioka, S., Arai, Y., et al. (2003). Brassinosteroid functions in a broad range of disease resistance in tobacco and rice. Plant J. 33, 887-898. doi: 10.1046/j.1365-313X.2003.01675.x

Nakayama, A., Fukushima, S., Goto, S., Matsushita, A., Shimono, M., Sugano, S., et al. (2013). Genome-wide identification of WRKY45-regulated genes that mediate benzothiadiazole-induced defense responses in rice. BMC Plant Biol. 13:150. doi: 10.1186/1471-2229-13-150

Naseem, M., Philippi, N., Hussain, A., Wangorsch, G., Ahmed, N., and Dandekar, T. (2012). Integrated systems view on networking by hormones in Arabidopsis immunity reveals multiple crosstalk for cytokinin. Plant Cell 24, 1793-1814. doi: 10.1105/tpc.112.098335

Naseem, M., Woelfling, M., and Dandekar, T. (2014). Cytokinins for immunity beyond growth, galls and green islands. Trends Plant Sci. 19, 481-484. doi 10.1016/j.tplants.2014.04.001

Navarro, L., Bari, R., Achard, P., Lisón, P., Nemri, A., Harberd, N. P., et al. (2008). DELLAs control plant immune responses by modulating the balance of jasmonic acid and salicylic acid signaling. Curr. Biol. 18, 650-655. doi: 10.1016/j.cub.2008.03.060

Nino-Liu, D. O., Ronald, P. C., and Bogdanove, A. J. (2006). Xanthomonas oryzae pathovars: model pathogens of a model crop. Mol. Plant Pathol. 7, 303-324. doi: 10.1111/j.1364-3703.2006.00344.x

Pan, X., Li, Y., Zhang, H., Huang, R., Liu, W., Ming, J., et al. (2014). Expression of signalling and defence-related genes mediated by over-expression of JERF1, and increased resistance to sheath blight in rice. Plant Pathol. 63, 109-116. doi: 10.1111/ppa.12064

Peng, X., Hu, Y., Tang, X., Zhou, P., Deng, X., Wang, H., et al. (2012). Constitutive expression of rice WRKY30 gene increases the endogenous jasmonic acid accumulation, PR gene expression and resistance to fungal pathogens in rice. Planta 236, 1485-1498. doi: 10.1007/s00425-012-1698-7

Pieterse, C. M. J., Leon-Reyes, A., Van der Ent, S., and Van Wees, S. C. M. (2009). Networking by small-molecule hormones in plant immunity. Nat. Chem. Biol. 5 , 308-316. doi: 10.1038/nchembio. 164

Pieterse, C. M. J., Van der Does, D., Zamioudis, C., Leon-Reyes, A., and Van Wees, S. C. M. (2012). Hormonal modulation of plant immunity. Annu. Rev. Cell Dev. Biol. 28, 489-521. doi: 10.1146/annurev-cellbio-092910-154055

Qi, J., Zhou, G., Yang, L., Erb, M., Lu, Y., Sun, X., etal. (2011). The chloroplast-localized phospholipases $\mathrm{D} \alpha 4$ and $\alpha 5$ regulate herbivore-induced direct and indirect defenses in rice. Plant Physiol. 157, 1987-1999. doi: 10.1104/pp.111.183749

Qin, X., Liu, J. H., Zhao, W. S., Chen, X. J., Guo, Z. J., and Peng, Y. L. (2013). Gibberellin 20-oxidase gene OsGA20ox3 regulates plant stature and disease development in rice. Mol. Plant Microbe Interact. 26, 227-239. doi: 10.1094/mpmi-05-12-0138-r

Qiu, D., Xiao, J., Xie, W., Cheng, H., Li, X., and Wang, S. (2009). Exploring transcriptional signalling mediated by OsWRKY13, a potential regulator of multiple physiological processes in rice. BMC Plant Biol. 9:74-85. doi: 10.1186/1471-2229-9-74

Qiu, D., Xiao, J., Xie, W., Liu, H., Li, X., Xiong, L., et al. (2008). Rice gene network inferred from expression profiling of plants overexpressing OsWRKY13, a positive regulator of disease resistance. Mol. Plant 1, 538-551. doi: 10.1093/mp/ssn012

Qiu, D. Y., Xiao, J., Ding, X. H., Xiong, M., Cai, M., Cao, C. L., et al. (2007). OsWRKY13 mediates rice disease resistance by regulating defense-related genes in salicylate- and jasmonate-dependent signaling. Mol. Plant Microbe Interact. 20, 492-499. doi: 10.1094/mpmi-20-5-0492

Quilis, J., Penas, G., Messeguer, J., Brugidou, C., and Segundo, B. S. (2008). The Arabidopsis AtNPR1 inversely modulates defense responses against fungal, bacterial, or viral pathogens while conferring hypersensitivity to abiotic stresses in transgenic rice. Mol. Plant Microbe Interact. 21, 1215-1231. doi: 10.1094/mpmi-21-9-1215

Ribot, C., Hirsch, J., Balzergue, S., Tharreau, D., Nottéghem, J. L., Lebrun, M. H., et al. (2008). Susceptibility of rice to the blast fungus, Magnaporthe grisea. J. Plant Physiol. 165, 114-124. doi: 10.1016/j.jplph.2007.06.013

Riemann, M., Haga, K., Shimizu, T., Okada, K., Ando, S., Mochizuki, S., et al. (2013). Identification of rice allene oxide cyclase mutants and the function of jasmonate for defence against Magnaporthe oryzae. Plant J. 74, 226-238. doi: $10.1111 /$ tpj.12115

Robert-Seilaniantz, A., Grant, M., and Jones, J. D. G. (2011). Hormone crosstalk in plant disease and defense: more than just jasmonate-salicylate antagonism. Annu. Rev. Phytopathol. 49, 317-343. doi: 10.1146/annurev-phyto-073009-114447

Robert-Seilaniantz, A., Navarro, L., Bari, R., and Jones, J. D. G. (2007). Pathological hormone imbalances. Curr. Opin. Plant Biol. 10, 372-379. doi: 10.1016/j.pbi.2007.06.003

Saika, H., Okamoto, M., Miyoshi, K., Kushiro, T., Shinoda, S., Jikumaru, Y., et al. (2007). Ethylene promotes submergence-induced expression of OsABA8ox1, a gene that encodes ABA 8'-hydroxylase in rice. Plant Cell Physiol. 48, 287-298. doi: $10.1093 / \mathrm{pcp} / \mathrm{pcm} 003$

Sato, T., Miyanoiri, Y., Takeda, M., Naoe, Y., Mitani, R., Hirano, K., et al. (2014). Expression and purification of a GRAS domain of SLR1, the rice DELLA protein. Protein Expr. Purif. 95, 248-258. doi: 10.1016/j.pep.2014.01.006

Schwessinger, B., and Ronald, P. C. (2012). Plant innate immunity: perception of conserved microbial signatures. Annu. Rev. Plant Biol. 63, 451-482. doi: 10.1146/annurev-arplant-042811-105518

Seo, Y. S., Chern, M., Bartley, L. E., Han, M., Jung, K. H., Lee, I., et al. (2011). Towards establishment of a rice stress response interactome. PLoS Genet. 7:e1002020. doi: 10.1371/journal.pgen.1002020

Sharma, R., De Vleesschauwer, D., Sharma, M. K., and Ronald, P. C. (2013). Recent advances in dissecting stress-regulatory crosstalk in rice. Mol. Plant 6, 250-260. doi: $10.1093 / \mathrm{mp} / \mathrm{sss} 147$

Shen, X. L., Liu, H. B., Yuan, B., Li, X. H., Xu, C. G., and Wang, S. P. (2011). OsEDR1 negatively regulates rice bacterial resistance via activation of ethylene biosynthesis. Plant Cell Environ. 34, 179-191. doi: 10.1111/j.1365-3040.2010. 02219.x

Shi, H., Shen, Q., Qi, Y., Yan, H., Nie, H., Chen, Y., et al. (2013). BR-signaling kinase1 physically associates with flagellin sensing 2 and regulates plant innate immunity in Arabidopsis. Plant Cell 25, 1143-1157. doi: 10.1105/tpc.112.107904

Shimono, M., Koga, H., Akagi, A. Y. A., Hayashi, N., Goto, S., Jiang, C., et al. (2012). Rice WRKY45 plays important roles in fungal and bacterial disease resistance. Mol. Plant Pathol. 13, 83-94. doi: 10.1111/J.1364-3703.2011.00732.x

Shimono, M., Sugano, S., Nakayama, A., Jiang, C. J., Ono, K., Toki, S., et al. (2007). Rice WRKY45 plays a crucial role in benzothiadiazole-inducible blast resistance. Plant Cell 19, 2064-2076. doi: 10.1105/tpc.106.046250

Siemens, J., Keller, I., Sarx, J., Kunz, S., Schuller, A., Nagel, W., et al. (2006). Transcriptome analysis of Arabidopsis clubroots indicate a key role for cytokinins in disease development. Mol. Plant Microbe Interact. 19, 480-494. doi: 10.1094/mpmi-19-0480 
Silverman, P., Seskar, M., Kanter, D., Schweizer, P., Metraux, J. P., and Raskin, I. (1995). Salicylic acid in rice: biosynthesis, conjugation, and possible role. Plant Physiol. 108, 633-639. doi: 10.1104/pp.108.2.633

Singh, M. P., Lee, F. N., Counce, P. A., and Gibbons, J. H. (2004). Mediation of partial resistance to rice blast through anaerobic induction of ethylene. Phytopathology 94, 819-825. doi: 10.1094/PHYTO.2004.94.8.819

Spoel, S. H., Koornneef, A., Claessens, S. M. C., Korzelius, J. P., Van Pelt, J. A., Mueller, M. J., et al. (2003). NPR1 modulates cross-talk between salicylate- and jasmonate-dependent defense pathways through a novel function in the cytosol. Plant Cell 15, 760-770. doi: 10.1105/tpc.009159

Spoel, S. H., Mou, Z., Tada, Y., Spivey, N. W., Genschik, P., and Dong, X. (2009). Proteasome-mediated turnover of the transcription coactivator NPR1 plays dual roles in regulating plant immunity. Cell 137, 860-872. doi: 10.1016/j.cell.2009.03.038

Sugano, S., Jiang, C. J., Miyazawa, S. I., Masumoto, C., Yazawa, K., Hayashi, N., et al. (2010). Role of OsNPR1 in rice defense program as revealed by genomewide expression analysis. Plant Mol. Biol. 74, 549-562. doi: 10.1007/s11103-010-9695-3

Swartzberg, D., Kirshner, B., Rav-David, D., Elad, Y., and Granot, D. (2008). Botrytis cinerea induces senescence and is inhibited by autoregulated expression of the IPT gene. Eur. J. Plant Pathol. 120, 289-297. doi: 10.1007/s10658-007-9217-6

Tada, Y., Spoel, S. H., Pajerowska-Mukhtar, K., Mou, Z., Song, J., Wang, C., et al. (2008). Plant immunity requires conformational charges of NPR1 via $S$-nitrosylation and thioredoxins. Science 321, 952-956. doi: 10.1126/science. 1156970

Taheri, P., and Tarighi, S. (2010). Riboflavin induces resistance in rice against Rhizoctonia solani via jasmonate-mediated priming of phenylpropanoid pathway. J. Plant Physiol. 167, 201-208. doi: 10.1016/j.jplph.2009.08.003

Takatsuji, H., and Jiang, C. J. (2014). "Plant hormone crosstalks under biotic stresses," in Phytohormones: A Window to Metabolism, Signaling and Biotechnological Applications, eds L. S. P. Tran and S. Pal (New York: Springer), 323-350. doi: 10.1007/978-1-4939-0491-4

Takatsuji, H., Jiang, C. J., and Sugano, S. (2010). Salicylic acid signaling pathway in rice and the potential applications of its regulators. Jpn. Agric. Res. Q. 44, 217-223. doi: 10.6090/jarq.44.217

Takeuchi, K., Gyohda, A., Tominaga, M., Kawakatsu, M., Hatakeyama, A., Ishii, N., et al. (2011). RSOsPR10 expression in response to environmental stresses is regulated antagonistically by jasmonate/ethylene and salicylic acid signaling pathways in rice roots. Plant Cell Physiol. 52, 1686-1696. doi: 10.1093/pcp/ pcr105

Tamaoki, D., Seo, S., Yamada, S., Kano, A., Miyamoto, A., Shishido, H., et al. (2013). Jasmonic acid and salicylic acid activate a common defense system in rice. Plant Signal. Behav. 8:e24260. doi: 10.4161/psb.24260

Tanaka, N., Matsuoka, M., Kitano, H., Asano, T., Kaku, H., and Komatsu, S. (2006). gid1, a gibberellin-insensitive dwarf mutant, shows altered regulation of probenazole-inducible protein (PBZ1) in response to cold stress and pathogen attack. Plant Cell Environ. 29, 619-631. doi: 10.1111/j.1365-3040.2005.01441.x

Taniguchi, S., Hosokawa-Shinonaga, Y., Tamaoki, D., Yamada, S., Akimitsu, K., and Gomi, K. (2014). Jasmonate induction of the monoterpene linalool confers resistance to rice bacterial blight and its biosynthesis is regulated by JAZ protein in rice. Plant Cell Environ. 37, 451-461. doi: 10.1111/pce.12169

Tao, Z., Liu, H., Qiu, D., Zhou, Y., Li, X., Xu, C., et al. (2009). A pair of allelic WRKY genes play opposite roles in rice-bacteria interactions. Plant Physiol. 151, 936-948. doi: 10.1104/pp.109.145623

Thaler, J. S., Humphrey, P. T., and Whiteman, N. K. (2012). Evolution of jasmonate and salicylate signal crosstalk. Trends Plant Sci. 17, 260-270. doi: 10.1016/j.tplants.2012.02.010

Thaler, J. S., Owen, B., and Higgins, V. J. (2004). The role of the jasmonate response in plant susceptibility to diverse pathogens with a range of lifestyles. Plant Physiol. 135, 530-538. doi: 10.1104/pp.104.041566

Tintor, N., Ross, A., Kanehara, K., Yamada, K., Fan, L., Kemmerling, B., et al. (2013). Layered pattern receptor signaling via ethylene and endogenous elicitor peptides during Arabidopsis immunity to bacterial infection. Proc. Natl. Acad. Sci. U.S.A. 110, 6211-6216. doi: 10.1073/pnas.1216780110

Tong, X., Qi, J., Zhu, X., Mao, B., Zeng, L., Wang, B., et al. (2012). The rice hydroperoxide lyase OsHPL3 functions in defense responses by modulating the oxylipin pathway. Plant J. 71, 763-775. doi: 10.1111/j.1365-313X.2012.05027.x

Truman, W. M., Bennett, M. H., Turnbull, C. G. N., and Grant, M. R. (2010). Arabidopsis auxin mutants are compromised in systemic acquired resistance and exhibit aberrant accumulation of various indolic compounds. Plant Physiol. 152, 1562-1573. doi: 10.1104/pp.109.152173

Tsuda, K., Sato, M., Stoddard, T., Glazebrook, J., and Katagiri, F. (2009). Network properties of robust immunity in plants. PLoS Genet. 5:e1000772. doi: 10.1371/journal.pgen.1000772

Ueno, Y., Yoshida, R., Kishi-Kaboshi, M., Matsushita, A., Jiang, C. J., Goto, S., et al. (2013). MAP kinases phosphorylate rice WRKY45. Plant Signal. Behav. 8:e24510. doi: $10.4161 /$ psb. 24510

Van der Does, D., Leon-Reyes, A., Koornneef, A., Van Verk, M. C., Rodenburg, N., Pauwels, L., et al. (2013). Salicylic acid suppresses jasmonic acid signaling downstream of SCFCOI1-JAZ by targeting GCC promoter motifs via transcription factor ORA59. Plant Cell 25, 744-761. doi: 10.1105/tpc.112.108548

van der Ent, S., and Pieterse, C. M. J. (2012). Ethylene: multi-tasker in plant-attacker interactions. Annu. Plant Rev. 44, 343-377. doi: 10.1002/9781118223086.ch13

Vlot, A. C., Dempsey, D. A., and Klessig, D. F. (2009). Salicylic acid, a multifaceted hormone to combat disease. Annu. Rev. Phytopathol. 47, 177-206. doi: 10.1146/annurev.phyto.050908.135202

Walters, D. R., McRoberts, N., and Fitt, B. D. L. (2008). Are green islands red herrings? Significance of green islands in plant interactions with pathogens and pests. Biol. Rev. 83, 79-102. doi: 10.1111/j.1469-185X.2007. 00033.x

Wang, D., Amornsiripanitch, N., and Dong, X. (2006). A genomic approach to identify regulatory nodes in the transcriptional network of systemic acquired resistance in plants. PLoS Pathog. 2:e123. doi: 10.1371/journal.ppat.0020123

Wang, Q., Li, J., Hu, L., Zhang, T., Zhang, G., and Lou, Y. (2013). OsMPK3 positively regulates the JA signaling pathway and plant resistance to a chewing herbivore in rice. Plant Cell Rep. 32, 1075-1084. doi: 10.1007/s00299-013-1389-2

Weiner, J. J., Peterson, F. C., Volkman, B. F., and Cutler, S. R. (2010). Structural and functional insights into core ABA signaling. Curr. Opin. Plant Biol. 13, 495-502. doi: 10.1016/j.pbi.2010.09.007

Westfall, C. S., Herrmann, J., Chen, Q., Wang, S., and Jez, J. M. (2010). Modulating plant hormones by enzyme action: the GH3 family of acyl acid amido synthetases. Plant Signal. Behav. 5, 1607-1612. doi: 10.4161/psb.5.12.13941

Wild, M., Davière, J.-M., Cheminant, S., Regnault, T., Baumberger, N., Heintz, D., et al. (2012). The Arabidopsis DELLA RGA-LIKE3 is a direct target of MYC2 and modulates jasmonate signaling responses. Plant Cell 24, 3307-3319. doi: $10.1105 /$ tpc.112.101428

Wu, Y., Zhang, D., Chu, J. Y., Boyle, P., Wang, Y., Brindle, I. D., et al. (2012). The Arabidopsis NPR1 protein is a receptor for the plant defense hormone salicylic acid. Cell Rep. 1, 639-647. doi: 10.1016/j.celrep.2012.05.008

Xiao, J., Cheng, H., Li, X., Xiao, J., Xu, C., and Wang, S. (2013). Rice WRKY13 regulates crosstalk between abiotic and biotic stress signaling pathways by selective binding to different cis-elements. Plant Physiol. 163, 1868-1882. doi: $10.1104 /$ pp.113.226019

Xiong, L., and Yang, Y. (2003). Disease resistance and abiotic stress tolerance in rice are inversely modulated by an abscisic acid-inducible mitogen-activated protein kinase. Plant Cell 15, 745-759. doi: 10.1105/tpc.008714

Xu, J., Audenaert, K., Höfte, M., and De Vleesschauwer, D. (2013). Abscisic acid promotes susceptibility to the rice leaf blight pathogen Xanthomonas oryzae pv. oryzae by suppressing salicylic acid-mediated defenses. PLOS ONE 8:e67413. doi: 10.1371/journal.pone.0067413

Yamada, S., Kano, A., Tamaoki, D., Miyamoto, A., Shishido, H., Miyoshi, S., et al. (2012). Involvement of OsJAZ8 in jasmonate-induced resistance to bacterial blight in rice. Plant Cell Physiol. 53, 2060-2072. doi: 10.1093/pcp/ pcs 145

Yang, D. L., Li, Q., Deng, Y. W., Lou, Y. G., Wang, M. Y., Zhou, G. X., et al. (2008). Altered disease development in the eui mutants and Eui overexpressors indicates that gibberellins negatively regulate rice basal disease resistance. Mol. Plant 1, 528-537. doi: 10.1093/mp/ssn 021

Yang, D. L., Yang, Y., and He, Z. (2013). Roles of plant hormones and their interplay in rice immunity. Mol. Plant 6, 675-685. doi: 10.1093/mp/sst056

Yang, D. L., Yao, J., Mei, C. S., Tong, X. H., Zeng, L. J., Li, Q., et al. (2012). Plant hormone jasmonate prioritizes defense over growth by interfering with gibberellin signaling cascade. Proc. Natl. Acad. Sci. U.S.A. 109, E1192-E1200. doi: 10.1073/pnas.1201616109

Yang, Y. N., Qi, M., and Mei, C. S. (2004). Endogenous salicylic acid protects rice plants from oxidative damage caused by aging as well as biotic and abiotic stress. Plant J. 40, 909-919. doi: 10.1111/j.1365-313X.2004.02267.x 
Ye, M., Luo, S. M., Xie, J. F., Li, Y. F., Xu, T., Liu, Y., et al. (2012). silencing COI1 in rice increases susceptibility to chewing insects and impairs inducible defense. PLoS ONE 7:e36214. doi: 10.1371/journal.pone.0036214

Yoshioka, K., Kachroo, P., Tsui, F., Sharma, S. B., Shah, J., and Klessig, D. F. (2001). Environmentally sensitive, SA-dependent defense responses in the cpr22 mutant of Arabidopsis. Plant J. 26, 447-459. doi: 10.1046/j.1365-313X.2001.26 41039.x

Yuan, Y. X., Zhong, S. H., Li, Q., Zhu, Z. R., Lou, Y. G., Wang, L. Y., et al. (2007). Functional analysis of rice NPR1-like genes reveals that OsNPR1/NH1 is the rice orthologue conferring disease resistance with enhanced herbivore susceptibility. Plant Biotechnol. J. 5, 313-324. doi: 10.1111/j.1467-7652.2007. 00243.x

Zhang, Y. L., Fan, W. H., Kinkema, M., Li, X., and Dong, X. N. (1999). Interaction of NPR1 with basic leucine zipper protein transcription factors that bind sequences required for salicylic acid induction of the PR-1 gene. Proc. Natl. Acad. Sci. U.S.A. 96, 6523-6528. doi: 10.1073/pnas.96.11.6523

Zhang, Z., Li, Q., Li, Z., Staswick, P. E., Wang, M., Zhu, Y., et al. (2007). Dual regulation role of $\mathrm{GH} 3.5$ in salicylic acid and auxin signaling during Arabidopsis-Pseudomonas syringae interaction. Plant Physiol. 145, 450-464. doi: 10.1104/pp.107.106021

Zhou, G., Qi, J., Ren, N., Cheng, J., Erb, M., Mao, B., et al. (2009). Silencing OsHILOX makes rice more susceptible to chewing herbivores, but enhances resistance to a phloem feeder. Plant J. 60, 638-648. doi: 10.1111/j.1365-313X.2009.03988.x

Zhou, G., Ren, N., Qi, J., Lu, J., Xiang, C., Ju, H., et al. (2014). The 9-lipoxygenase Osr9-LOX1 interacts with the 13-lipoxygenase-mediated pathway to regulate resistance to chewing and piercing-sucking herbivores in rice. Physiol. Plant. 152, 59-69. doi: 10.1111/ppl.12148

Zhou, N., Tootle, T. L., Tsui, F., Klessig, D. F., and Glazebrook, J. (1998). PAD4 functions upstream from salicylic acid to control defense responses in Arabidopsis. Plant Cell 10, 1021-1030. doi: 10.1105/tpc.10.6.1021

Zipfel, C. (2008). Pattern-recognition receptors in plant innate immunity. Curr. Opin. Immunol. 20, 10-16. doi: 10.1016/j.coi.2007.11.003

Conflict of Interest Statement: The authors declare that the research was conducted in the absence of any commercial or financial relationships that could be construed as a potential conflict of interest.

Received: 16 September 2014; accepted: 20 October 2014; published online: 11 November 2014.

Citation: De Vleesschauwer D, Xu J and Höfte M (2014) Making sense of hormonemediated defense networking: from rice to Arabidopsis. Front. Plant Sci. 5:611. doi: 10.3389/fpls.2014.00611

This article was submitted to Plant-Microbe Interaction, a section of the journal Frontiers in Plant Science.

Copyright (c) 2014 De Vleesschauwer, Xu and Höfte. This is an open-access article distributed under the terms of the Creative Commons Attribution License (CC BY). The use, distribution or reproduction in other forums is permitted, provided the original author(s) or licensor are credited and that the original publication in this journal is cited, in accordance with accepted academic practice. No use, distribution or reproduction is permitted which does not comply with these terms. 